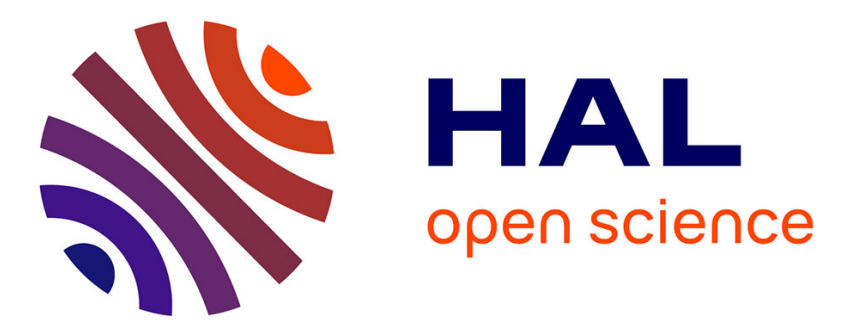

\title{
The Repetitive Content in Lupin Genomes
}

Abdelkader Ainouche, Aurore Paris, Delphine Giraud, Jean Keller, Pauline Raimondeau, Frédéric Mahe, Pavel Neuman, Petr Novak, Jiri Macas, Lily Ainouche Malika, et al.

\section{- To cite this version:}

Abdelkader Ainouche, Aurore Paris, Delphine Giraud, Jean Keller, Pauline Raimondeau, et al.. The Repetitive Content in Lupin Genomes. Singh Karam B. (ed.); Kamphuis Lars G. (ed.); Nelson Matthew N. (ed.). The Lupin Genome, Springer, pp.161-186, 2020, 978-3-030-21270-4; 978-3-03021269-8. 10.1007/978-3-030-21270-4_12 . hal-02879117

\section{HAL Id: hal-02879117 https://hal-univ-rennes1.archives-ouvertes.fr/hal-02879117}

Submitted on 23 Jun 2020

HAL is a multi-disciplinary open access archive for the deposit and dissemination of scientific research documents, whether they are published or not. The documents may come from teaching and research institutions in France or abroad, or from public or private research centers.
L'archive ouverte pluridisciplinaire $\mathbf{H A L}$, est destinée au dépôt et à la diffusion de documents scientifiques de niveau recherche, publiés ou non, émanant des établissements d'enseignement et de recherche français ou étrangers, des laboratoires publics ou privés. 


\title{
12 The repetitive content in lupin genomes
}

\author{
Abdelkader Aïnouche ${ }^{1}$, Aurore Paris ${ }^{1}$, Delphine Giraud ${ }^{1}$, Jean \\ Keller $^{1,2}$, Pauline Raimondeau ${ }^{1}$, Frédéric Mahé ${ }^{3}$, Pavel \\ Neuman ${ }^{4}$, Petr Novak ${ }^{4}$, Jiri Macas ${ }^{4}$, Malika Aïnouche ${ }^{1}$, Armel \\ Salmon ${ }^{1}$, Guillaume E. Martin 5 .
}

Corresponding author: kader.ainouche@univ-rennes1.fr

${ }^{1}$ UMR CNRS 6553 ECOBIO, Université de Rennes 1, 35042

Rennes cedex, France.

${ }^{2}$ Laboratoire de Recherche en Sciences Végétales, Université de Toulouse, CNRS, UPS, 24 chemin de Borde Rouge, Auzeville, BP42617, 31326 Castanet-Tolosan, France

${ }^{3}$ CIRAD (Centre de coopération Internationale en Recherche Agronomique pour le Développement), Campus international de Baillarguet, 34398 Montpellier Cedex 5, France

${ }^{4}$ Biology Centre of the Czech Academy of Sciences, Laboratory of Molecular Cytogenetics, Institute of Plant Molecular Biology, Branisovska 31, Ceske Budejovice, CZ-37005, Czech Republic

${ }^{5}$ CIRAD (Centre de coopération Internationale en Recherche Agronomique pour le Développement), UMR AGAP, F-34398 Montpellier, France 
Abstract In this chapter, we present the first detailed evaluation of the repetitive compartment in Lupinus genomes. Low-depth next generation sequencing (NGS) genomic resources from four closely related smooth-seeded Mediterranean lupin species (L. albus, L. angustifolius, L. luteus and L. micranthus), exhibiting remarkable differences in genome size and chromosome number have been investigated. The repetitive compartment is composed of a wide diversity of repeats and represents 23 to $51 \%$ of the genomes. This compartment is essentially comprised of transposable elements (43 to $85 \%$ ), mainly represented by copia and gypsy LTR retrotransposon families. Among the latter, some prominent families (Tekay, Athila, Maximus-SIRE) significantly contribute to genome size differences among species and in shaping different species-specific repeat profiles, regardless of their chromosome numbers. Also particular lineages of these elements have been differentially and recently amplified within species, such as in L. luteus, L. albus and $L$. angustifolius. Moreover, this study highlighted the diversity of tandem repeats in lupin genomes, with minisatellites and satellites mostly being species-specific, whereas microsatellites (SSRs) are ubiquitously distributed. Strikingly, L. angustifolius exhibited a tremendous amount of tandem repeats in its genome (26\%), including a noteworthy accumulation of one particular hexamer SSR (15.24\% of the genome), which demonstrate that also tandem repeats may greatly contribute to genome obesity and dynamics in lupins. Therefore, differential lineage-specific amplifications of retrotransposons and tandem repeats occurred among lupins. Accordingly, this strongly 
suggests that different processes and mechanisms regulating amplification, proliferation and clearance of repeats have differentially operated within the same genus among closely related Mediterranean species over the last $\sim 10-12$ Myr. Further extension of such evaluation to various representatives of the lupins diversity and outgroups will provide a better overview of the repetitive compartment and its evolutionary dynamics in the genus. Additionally, the genomic resources generated by this work represent a valuable basis to start building a repeats database specifically dedicated to best understand the genomic landscape, repeats distribution and localization in lupins. This will facilitate further investigations on the functional and evolutionary impact of repeats on genes of interest, such as, those responsive for important agronomical, adaptive and defense features. 


\subsection{INTRODUCTION}

Genome size variation, with a magnitude order of 200,000 , is one of the most remarkable biological features in Eucaryotes (Bennetzen and Wang, 2014; Biscotti et al., 2015). As this variation is not correlated with the morphological or physiological complexity of organisms it has been termed the "C-value paradox" (Thomas, 1971) and later the "C-value enigma" (Gregory, 2005). In angiosperms, genome size (GS) ranges from $60 \mathrm{Mb}$ (in Genlisea aurea) to $150 \mathrm{~Gb}$ (in Paris japonica), which corresponds to approximately a 2,400fold variation (Greilhuber et al., 2006; Leitch \& Leitch, 2008; Vu et al., 2015; Jaume Pellicer et al., 2018). Moreover, GS variation occurs at various taxonomic levels, including among closely related species within genera (Greilhuber et al., 2006; Hu et al., 2011) or even among various accessions within species, such as in Hordeum spontaneum (Kalendar et al., 2000) or in Arabidopsis thaliana (Schmuths, 2004). Apart from whole-genome duplication, triplication, or polyploidy (Soltis et al., 2009; Renny-Byfield \& Wendel, 2014), it is now obvious that repetitive sequences may account for a large proportion in the plant genomes, regardless of the number of protein coding genes, the ploidy level or the past paleopolyploid history (Bennetzen, 2002, 2005; Wendel et al., 2016). While, the repetitive sequences were previously regarded as "junk", "parasitic" or “selfish” DNA (Doolittle \& Sapienza, 1980; Orgel et al., 1980; Lönnig \& Saedler, 1997), nowadays they are not only considered as a determinant fraction involved in GS variation (expansion / contrac- 
tion), but also that they play a major role in their evolutionary dynamics and are crucial for living organisms (Biémont \& Vieira, 2006; Oliver et al., 2013; Wendel et al., 2016; Hosaka \& Kakutani, 2018; Pellicer et al., 2018). Two types of repetitive DNA sequences proliferate in the genomes: tandem repeats (or satellites sensu lato) and interspersed repeats (or transposable elements).

\subsubsection{Tandem repeats}

Tandem repeats (TR) consist of basic nucleotide units (or monomers) that are repeated head-to-tail to form TR arrays. According to the size of the repeated unit the tandem repeats are classified as: microsatellites or SSR (Simple Sequence Repeats) with motives shorter than 10-12 bp, minisatellites with motives between 12 to $\sim 60 \mathrm{bp}$, and satellites with longer monomers ( $>60$ to $100 \mathrm{bp}$ or even several kilobases). Increase (or decrease) of the number of repeated units in microsatellites, for instance, generally results from a "slipped-strand mispairing" mechanism due to a polymerase shift during DNA replication (Levinson \& Gutman, 1987) or unequal crossovers (Petes, 1980). Satellite DNA can represent up to half of the genome in some eukaryotes (Satović et al., 2018). Microsatellites (SSRs) are ubiquitous in genomes and are widely used as genetic markers for genotyping (Parra-González et al., 2012;.Raman et al., 2014; Kamphuis et al., 2015; Atnaf et al., 2017). The other larger arrays of TR, minisatellites, satelittes, including highly repetitive gene families such as nuclear ribosomal DNA, are helpful for chromosome fingerprinting. They are usually associated to centromeric, peri- 
centromeric and telomeric regions and seem to have a significant functional regulatory role (Streelman \& Kocher, 2002; Li, 2004; Lower et al., 2018), but they yet remain poorly investigated and were the subject of only few comparative genomics studies (Shi et al., 2013; Ruiz-Ruano et al., 2016; Usai et al., 2017).

\subsubsection{Transposable elements}

Transposable elements (TEs) are very diverse interspersed repetitive DNA sequences (or jumping genetic elements of B. McClintock, 1948) able to duplicate themselves and to insert their copies at different positions in the genome via a transposition mechanism (Kumar \& Bennetzen, 1999; Bennetzen, 2002). Following the classification of (Wicker et al., 2007), TEs are divided into two main classes, according to the type of intermediate (DNA or RNA) used in their transposition mode. Class I elements, or retrotransposons, follow a transposition mode using an RNA intermediate called "copy / paste", which may dramatically increase their copy number in genomes (Vicient et al., 1999; Bennetzen, 2002, 2005; Piegu et al., 2006). Five orders are distinguished within this class: LTR elements (Long Terminal Repeats) DIRS elements (Dictyostelium intermediate repeat sequence), PLEs (Penelope-like elements), LINEs (Long Interspersed Nuclear elements) and SINEs (Small Interspersed Nuclear Element). Within each order, elements are clustered into superfamilies based on the structure of their protein and non-coding domains. The Class II elements (or DNA transposons) transpose via a DNA intermediate in a mode called "cut / paste", which results in 
their excision from their genomic location and their insertion elsewhere in the genome. Two subclasses are recognized: subclass 1 mainly correspond to TIR elements, which are characterized by their Terminal Inverted Repeats (TIR) at their extremities; and subclass 2 which correspond to Helitron and Maverick elements (Wicker et al., 2007).

In plants, amplification and accumulation of Class I elements represent the major source of GS increase. For example, LTRretrotransposons may reach between $\sim 70$ to $76 \%$ of the genomes in maize, bread wheat and barley (Mayer et al., 2011; Oliver et al., 2013; Wicker et al., 2018). TEs amplification can be activated by various environmental (biotic and abiotic) and genomic (e.g., hybridizations) stresses during the evolutionary history of organisms (Kalendar et al., 2000; Liu \& Wendel, 2000; Jiang et al., 2003; Grandbastien et al., 2005; Wessler, 2006). In turn, different regulatory mechanisms are triggered at the cellular and molecular levels to control their proliferation and counteract genome expansion via epigenetic mechanisms (small RNA, DNA methylation, histone modification) and removal (Bennetzen, 2005; Hawkins et al., 2006, 2009; Slotkin \& Martienssen, 2007; Lisch, 2009; Yaakov \& Kashkush, 2012; Axtell, 2013; Castel \& Martienssen, 2013). The repeated waves of TE amplification and regulatory mechanisms thus have a deep impact on the host genomes. They may drive structural genomic rearrangements and generate genetic diversity which accompanies the adaptation and diversification of species in their environments (Bennett, 2005; Morgante et al., 2005; Chénais et al., 2012). 
Following their insertion into or near genes, they may modify expression and function of various genes which may induce variable phenotypic changes (Jiang et al., 2003; Kashkush et al., 2003; Lisch, 2013). Also there is evidence that they contribute to the formation of new genes and represent an important source of evolutionary novelties (Biémont \& Vieira, 2006; Oliver et al., 2013; Lynch et al., 2015).

\subsubsection{Advancing the discovery of repetitive sequences using} Next Generation Sequencing technology

Regarding their importance, investigations on the repetitive sequences greatly benefited from the advances of high throughput sequencing technologies. Several strategies and bioinformatics programs have been developed for the detection and identification of repeated elements in fully sequenced genomes of model organisms (Quesneville et al., 2005; Lerat, 2010; Flutre et al., 2011; Treangen \& Salzberg, 2011; Wajid \& Serpedin, 2012). However, assembly, annotation and precise location of massive similar repeated shortreads, representing regions which underwent various processes of recombination/deletion, is challenging and generally results in incompletely assembled genomes with large gap-spaces and potentially chimerical structures (Jiang et al., 2004; Sequencing Project, 2005). Combination of short-reads technologies (Illumina HiSeq) with long-reads sequencing ones (Pacific BioSiences and Oxford Nanopore) will yield higher quality genomes to accurately assemble and circumscribe repeated structures. Other programs have been de- 
signed to directly evaluate the repetitive content from raw unassembled short read sequences generated from various high-throughput DNA sequencing technology platforms, such as for example: RepeatExplorer (Novák et al., 2010; Novak et al., 2013), Transposome (Staton, Burke, 2015), REPdenovo (Chu et al., 2016). Such programs use various tools which allow detection, quantitative estimation, reconstruction and annotation of repetitive elements in NGS data. They are based on all-to-all read sequence similarities, graphbased clustering methods, and repeats identification using complementary Blast methods and search of conserved specific TEs protein coding domains against reference databases. These toolkits demonstrated their efficiency for evaluating the repetitive compartment from a reduced sample of low-pass genome sequence data (even less than $1 \%$ genome coverage) in various plant taxa (Macas et al., 2007; Hřibová et al., 2010; Novák et al., 2010, 2013; Renny-Byfield et al., 2011; Piednoël et al., 2013; Staton, Burke, 2015; Vu et al., 2015; Wu et al., 2019). They not only allow rapid investigation of the repetitive compartment in many non-model genomes, but also may provide crucial information to assist assembly and annotation of complex genomes.

\subsubsection{Lupinus: A system of interest to evaluate the dynamics of} the genomic repetitive compartment

In this context, the genistoid legume Lupinus (Fabaceae) is a system of particular interest to explore the evolutionary dynamics of repetitive sequences and their impact on the evolution of host genomes. 
Indeed, Lupinus is a large genus which is composed of hundreds of species adapted to very divers ecological conditions which diversified during the last $\sim 16 \mathrm{Myr}$ (mean age of the stem node of the genus according to Hughes and Eastwood, 2006) in two major regions of the World: about 250-300 species in the New World and around 20 in the Old World (Gladstones et al., 1998; Ainouche et al., 2004; Eastwood et al., 2008). Among the latter, the smooth-seeded lupins (or Malacosperma), which are mainly circum-Mediterranean are distinguished from the rough-seeded lupins (or Scabrispermae), which are predominantly North African. Previous studies have shown that lupins exhibit a remarkable variation of their chromosome number $(2 \mathrm{n}=32$ to 52$)$ and their genome size $(2 \mathrm{C}=1$ to $\sim 2.6 \mathrm{~Gb})$, including between closely related taxa, regardless of their chromosome number (Gladstones et al., 1998; Naganowska, 2003; Naganowska et al., 2005; Conterato \& Schifino-Wittmann, 2006; Mahé, 2009). A first PCR-based screening of the repeated compartment revealed a significant diversity of LTR-retrotransposons in lupin genomes (Mahé, 2009). Because of their beneficial properties for agriculture, human health and nutrition (Gladstones et al., 1998; CabelloHurtado et al., 2016), and for their novel status as model plants for studying symbiosis, proteoid roots and Pi uptake (O'Rourke et al., 2013; Keller et al., 2018), the smooth-seeded Mediterranean lupins, which include three crops (L. albus, L. luteus and L. angustifolius), are under increasing attention. Several transcriptomes and genomic resources have been generated (see Section 4.X and 6.Y) (ParraGonzález et al., 2012; O’Rourke et al., 2013; Kamphuis et al., 2015; 
Keller et al., 2018) and a first draft genome has been recently released (Hane et al., 2017; this book), providing the raw material to best understand structure, evolution and functional potential of the lupin genome, including its repetitive compartment.

Therefore, as a first step to develop our knowledge on this enigmatic genomic compartment, we report results from: (i) a preliminary survey of the diversity of LTR-retotransposons (Tyl-copia and Ty3gypsy-like elements) in Lupinus and allied Genistoid taxa, based upon analysis of their reverse transcriptase sequences (RTs) (Flavell et al., 1992; Alix \& Heslop-Harrison, 2004; Mahé, 2009); and (ii) a detailed evaluation of the repetitive compartment of four smoothseeded Mediterranean lupin taxa, from the analysis of low-depth NGS genomic resources, using different programs to identify and estimate the repetitive sequences (Benson, 1999; Novák et al., 2010, 2017; Novak et al., 2013).

\subsection{Exploring retrotransposons diversity in genomes of lupins and allied Genistoids}

Ty1-copia-like and Ty3-gypsy-like superfamilies of class I retrotransposons are ubiquitous in eukaryote genomes and most often involved in genome size (GS) variation. A preliminary investigation of their diversity, was conducted in 44 accessions belonging to 27 lupin taxa (16 from the Old World and 11 from the New World) and 8 other Genistoid representatives; Table 13.1). This was carried out 
through analysis of their constitutive reverse transcriptase sequences (RTs) (Mahé, 2009). Accordingly, conserved coding RT domains were amplified, cloned and sequenced from genomic DNA samples using universal primers (Flavell et al., 1992) following the procedure described by Alix \& Heslop-Harrison, (2004). After (i) removing the low-quality sequences from the hundreds of amplicons generated, (ii) verifying their homology with known RTs from public databases (via Blastn, Blastx and RepeatMasker; http://www.ncbi.nlm.nih.gov and http://www.repeatmasker.org/), and (iii) size-filtering, a total of 367 retrotransposon-like RT sequences were selected for further analysis. Among them 260 amplicons ranged in size from 248 to $295 \mathrm{bp}$, with pairwise identity varying from 38.6 to $100 \%$ for copia elements (GenBank accession numbers GU189754 to GU190013); and 107 ranged from 366 to 564 bp with a pairwise identity of 32.4 to $100 \%$ for gypsy elements (accession numbers GU190014 to GU190133).

Within this set of amplicons, 305 were from the lupin species (211 RT-copia, 89 RT-gypsy and five unidentified) and 62 were from the eight Genistoid representatives (including 40 RT-copia, 17 RTgypsy and five unannotated). Altogether, these 367 DNA sequences were aligned with MAFFT (Katoh \& Standley, 2013). The sequence data matrix was then subjected to a maximum likelihood (ML) phylogenetic analysis, using the best-fitted evolutionary model (GTR+R7: General Time Reversible model, rates Gamma distributed) identified with ModelFinder (Kalyaanamoorthy et al., 2017) as 
implemented in IQ-TREE v1.5.5 (Nguyen et al., 2015). The robustness of the nodes was estimated with 10,000 ultrafast bootstrap replicates (Hoang et al., 2017). The phylogenetic tree resulting from this analysis is shown in Figure 13.1, where each terminal branch representing RT-copia or RT-gypsy amplicons is colored according to its taxonomic and geographic origin (see Fig. legends) and its annotation assignment indicated by different colors in the outer circle.

Table 13.1: List of accessions from Lupinus and other Genistoid taxa surveyed for retrotransposons diversity. The origin, geographic distribution, and accession reference are indicated for each sample. OW $=$ Old World species; NW = New World species .

\begin{tabular}{lcll}
\hline Taxon & 2n & Origin/Distribution & $\begin{array}{l}\text { Sample source \& Reference } \\
\text { number }\end{array}$ \\
\hline L. affinis & 48 & Oregon/NW, West NA & USDA/504315/N20 \\
L. albus & 50 & Algeria/OW, Med & INAE-DZ/M20 \\
L. anatolicus & 42 & Turkey/OW, Afr & AKA/K32 \\
L. angustifolius ssp. reticula- & & France/OW, Med & AKA/T25 \\
L. angustifolius ssp. angusti- & 40 & & \\
folius & 40 & Algeria/OW, Med & AKA-M1/T24 \\
L. atlanticus & 38 & Morocco/OW, Afr & USDA/384612-FM83/T1 \\
\hline & 38 & Morocco/OW, Afr & INRA-SAPF/T11 \\
& 38 & Morocco/OW, Afr & USDA/384613-FM87/T2 \\
L. bracteolaris & $32-$ & Brazil/NW, South-East & \\
L. concinnus & 34 & SA & USDA/404349/S80 \\
L. cosentinii & $?$ & USA/NW & N19 \\
L. diffusus & 32 & ?/OW, Med & INRAL-FR/T15 \\
L. digitatus & $?$ & Florida/NW & K35 \\
L. elegans & 36 & Egypt/OW, Afr-Med & WADA-PI26877/T4 \\
L. hirsutissimus & 48 & Mexico/NW, West SA & USDA/185099/S33 \\
L. hispanicus ssp. bicolor & $?$ & USA/NW & AKA/N85 \\
L. hispanicus ssp. hispanicus & 52 & Spain/OW, Med & USDA/PI 384554/T23 \\
L. luteus & 52 & Portugal/OW, Med & USDA/384555/T22 \\
& 52 & Algeria/OW, Med & AKA/M5 \\
\hline & 52 & Algeria/OW, Med & AKA/T20
\end{tabular}


L. mariae-josephi

L. micranthus

L. mutabilis

L. nanus

L. palaestinus

L. paraguariensis

L. pilosus

L. pilosus tassilicus

L. polyphyllus

L. princei

L. texensis

Anarthrophyllum cumingii

Argyrolobium uniflorum

Chamaecytisus mollis

Crotalaria podocarpa

Cytisus heterochrous

Genista tinctoria

Thermopsis rhombifolia

Ulex parviflorus
52 Algeria/OW, Med

52? Spain/OW, Med

2 Algeria/OW, Med

Algeria/OW, Med

Perou/NW, West SA

USA/NW

Near-East/OW, Afr-Med INRA-FR/T14

Brazil/NW, East SA

Algeria/OW, Afr-Med

Algeria/OW, Afr-Med

North-Africa/OW, Afr-

42 Med

? Lybia/OW, Afr

48 USA/NW, NA

Kenya/OW, Afr

Kenya/OW, Afr

Kenya/OW, Afr

36 USA/NW, South NA

? ?/NW, South SA

OW

? OW

? OW

? $\mathrm{OW}$

OW

NW

? Spain/OW, Med
AKA/T21

H. Pascual/MJ1

AKA/T19

T 28

INAE-DZ/S35/MU23

$\mathrm{N} 42$

BRA-02828/BZ1

INAE-DZ/T6

INAE-DZ/T9

USDA/W6 PI 11995/T13

AKA/A641

USDA/504404/T26

WADA P 23021/T0

RP Chyulu 1800/T16

RP Chyulu 1915/T17

USDA/577291/N45

AKA/201

AKA/G25

AKA/C84

AKA/K50

AKA/G8

AKA/G56

AKA/G46

AKA/G24 


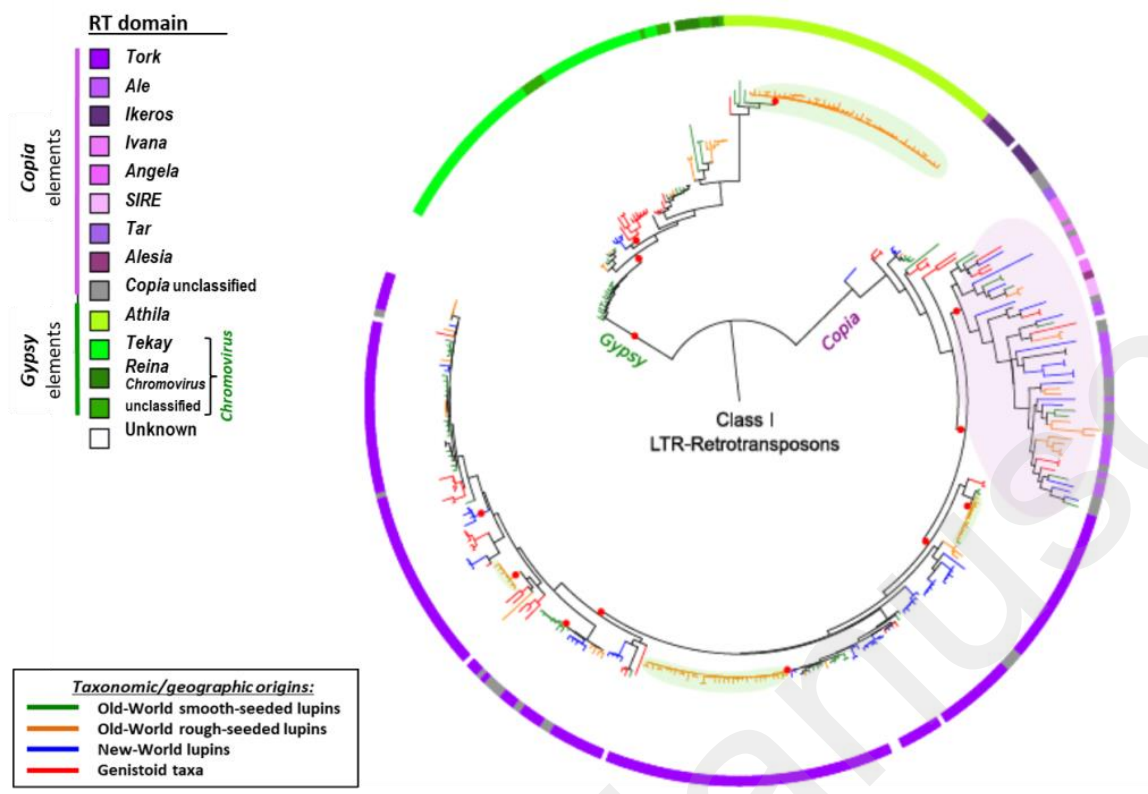

Figure 13.1: Maximum likelihood phylogenetic tree of 367 copia and gypsy RT fragments amplified from 44 accessions belonging to 27 Old World and New World lupin taxa (305 sequences) and from 8 other Genistoid representatives (62 sequences). Each terminal branch is colored according to its taxonomical/geographical group of origin and its copia or gypsy annotation assignment indicated by different colors in the outer circle (see legends in the figure). Red dots on the tree indicate remarkable well supported nodes (by bootstrap estimate). Some remarkable groups of copia or gypsy amplicons likely representing ubiquitous elements of ancient origin (shaded in mauve) or recent lineage-specific amplifications (shaded in light green) are also indicated.

A remarkable diversity of retrotransposon elements was detected within genomes of both lupin and Genistoid species. Random amplified RT sequences using universal primers allowed a clear segrega- 
tion of the two retrotransposon superfamilies, with a higher amplification success for the copia ones. Within each of these superfamilies, several families have been identified: mainly Tork copia-like elements and at a lower scale other copia families (Ale, Ikeros, Ivana, Angela, SIRE, Tar and Alesia). Whereas gypsy-like elements were mainly represented by Tekay and Athila elements, and few Reina and Tat/Ogre ones. Most of them showed significant levels of RT-identity with those from other Fabaceae available in databases for Cicer (52.5-88.4\%), Vigna (51-86 \%), Vicia, or Soybean, suggesting that these elements were most likely inherited from a common Papilionoid ancestor or even from earlier origin.

Although the number of amplicons is low for some taxa, the main retrotransposons families detected appear to be ubiquitous throughout the lupine and Genistoid genomes, as illustrated by the presence of multicolored branches in each of the main copia and gypsy clades in Figure 13.1). One remarkable and well-supported multicolored clade (shaded in mauve) of related copia elements (Alesia, SIRE, Angela, Ivana) includes highly divergent RT-sequences (with long evolutionary branches) from most lupin and Genistoid taxonomic and geographical groups. This suggests that they likely derive from a common and ancient ancestor. The other noteworthy groups revealed by the phylogeny are those including weakly divergent sequences isolated from the same taxonomic or geographical lineage (shaded in light green), indicating recent lineage-specific transpositional activities. This is particularly well exemplified by several spe- 
cific retrotransposon families (groups with monochrome branches) observed in the tree for: the rough seeded Old World lupins with orange branches (Athila and Tork); the smooth seeded Old World lupins with green branches (Tekay and Tork); the New World lupins with blue branches (Tork groups); and in the Genistoids with red branches (a Tekay group). Other homogeneous lineage-specific groups are composed of more divergent RT sequences likely deriving from earlier transposition events, such as for instance in the Genistoids (red branches) which show specific lines of Athila and Tork elements.

Within the collection of conserved RT domains generated from the lupins, five were amplified from a sample of $L$. angustifolius subsp. angustifolius (originating from North Africa), three RT-gypsy and two RT-copia clones. These clones have been used as queries in a rapid screening of the current reference NLL genome (of L. angustifolius cultivar. Tanjil; (Hane et al., 2017)) to estimate a potential number of PCR-based amplified products that could be expected from this genome. Interestingly, no less than 997 and 1209 non redundant hits were found for the gypsy and the copia elements, respectively, using the easy Blast search tool (with evalue threshold: 1.0e-5) implemented in the Lupin Genome Portal https:// www.lupinexpress.org/ (Priyam et al., 2015).

Therefore, despite an inevitably biased sampling due to the intrinsic limits of the method (related to variable rates of RT degeneracy within and among genomes, to the performance of the "universal 
primers", and depending on the cloning and sequencing depth), the PCR-based exploration of the lupin and Genistoid genomes allowed detection of a wide diversity of copia-like and gypsy-like LTRretrotransposons families. Most of them are ubiquitous throughout the lupins and Genistoids. Moreover, phylogenetic analysis of the RT-sequences provided clues which suggest that some retrotransposons subfamilies seem to have differentially and specifically proliferated (bursts) during the recent evolutionary history of the genus in the New and the Old World lupins. Besides, a fluorescence in situ hybridization (FISH) test performed on metaphase root cells of Old World lupines using copia ant gypsy RT-probes (Mahé, 2009) indicated a much higher accumulation of retrotransposons in the large genome of the Mediterranean species L. luteus $(2367 \mathrm{Mb} / 2 \mathrm{C})$ than in the small genome of L. micranthus (1147 Mb/2C). Thus, altogether these results emphasized the need to more accurately identify and evaluate the diversity and relative abundance of transposable elements.

\subsection{NGS-based evaluation of the repetitive compartment in lu- pin genomes}

As highlighted, lupins are characterized by a noteworthy genome sizes variation ( $\mathrm{GS}=2 \mathrm{C}=$ nuclear DNA amount per cell) ranging from 1.05 to $2.6 \mathrm{~Gb}$, regardless of their various chromosome numbers (varying from $2 \mathrm{n}=32,34,36,38,40,42,48,50$ to 52 ). This is observable even between taxa having the same chromosome number (such as L. luteus which has more than twice the size of that of $L$. 
micranthus), as well as regardless of their Old World or New World origins and of their phylogenetic relationships.

Therefore, in order to deepen our understanding of the lupin genome dynamics, four lupin accessions with small and large genomes, belonging to different Mediterranean Old World smooth-seeded species (Table 13.2; Figure 13.2), were subjected to a comparative NGS-based analysis of their genomic repetitive compartment: L. albus $(2 \mathrm{n}=50 ; 2 \mathrm{C}=1.13 \mathrm{~Gb}), L$. angustifolius $(2 \mathrm{n}=40 ; 2 \mathrm{C}=1.85 \mathrm{~Gb}), L$. luteus $(2 \mathrm{n}=52 ; 2 \mathrm{C}=2.37 \mathrm{~Gb})$, and L. micranthus $(2 \mathrm{n}=52 ; 2 \mathrm{C}=1.15$ Gb). For this purpose, a sequence dataset of 1,200,000 Paired-End $100 \mathrm{bp}$ reads $(120 \mathrm{Mb})$ per accession, extracted from resources generated by low-depth genomic Illumina HiSeq sequencing, and representing 5 to $10 \%$ of each genome (Table 13.2), was analyzed with RepeatExplorer (Novák et al., 2010; Novak et al., 2013). Following analysis of a combined data set (including 4,800,000 reads, each labeled according to its species origin), 293,635 clusters were obtained. Among the 744 clusters containing more than 48 reads (the largest having 265,540 reads), 176 were annotated as transposable elements and 207 as simple sequence repeats; the remaining clusters corresponded to organelle or to unclassified sequences. 
Table 13.2: Origins and characteristics of the genomic resources of four Lupinus species used in this study.

\begin{tabular}{|l|c|c|c|c|c|c|c|c|}
\hline & $\begin{array}{c}\text { Acces- } \\
\text { sion code }\end{array}$ & Origins & $2 n$ & $\begin{array}{c}2 \mathrm{C} \\
\text { DNA } \\
\text { amount* } \\
\text { (in } \mathrm{pg})\end{array}$ & $\begin{array}{c}\text { Genome } \\
\text { Size** } \\
(2 \mathrm{C} \text { in } \\
\mathrm{Mb})\end{array}$ & $\begin{array}{c}\text { Total length of } \\
\text { reads sequenced } \\
(\mathrm{Gb})\end{array}$ & $\begin{array}{c}\text { Genome } \\
\text { coverage } \\
\text { (x folds) }\end{array}$ & $\begin{array}{c}\text { \% of genome } \\
\text { analyzed with } \\
\text { RE*** }\end{array}$ \\
\hline $\begin{array}{l}\text { L. albus } \\
\begin{array}{l}\text { L. angusti- } \\
\text { folius }\end{array}\end{array}$ & $\mathrm{M} 20$ & Egypt & 50 & 1,16 & 1134,48 & 1.2 & 1.06 & $10.57 \%$ \\
$\begin{array}{l}\text { L. luteus } \\
\text { L. micran- } \\
\text { thus }\end{array}$ & $\mathrm{M} 6$ & Morocco & 40 & 1.89 & 1848.42 & 15.4 & 8.2 & $6.5 \%$ \\
\hline
\end{tabular}

*According to (Naganowska, 2003) and (Mahé, 2009)

** Using $1 \mathrm{pg}=978 \mathrm{Mb}$ according to (Dolezel et al., 2003)

***Repeat Explorer (Novák et al., 2010; Novak et al., 2013)

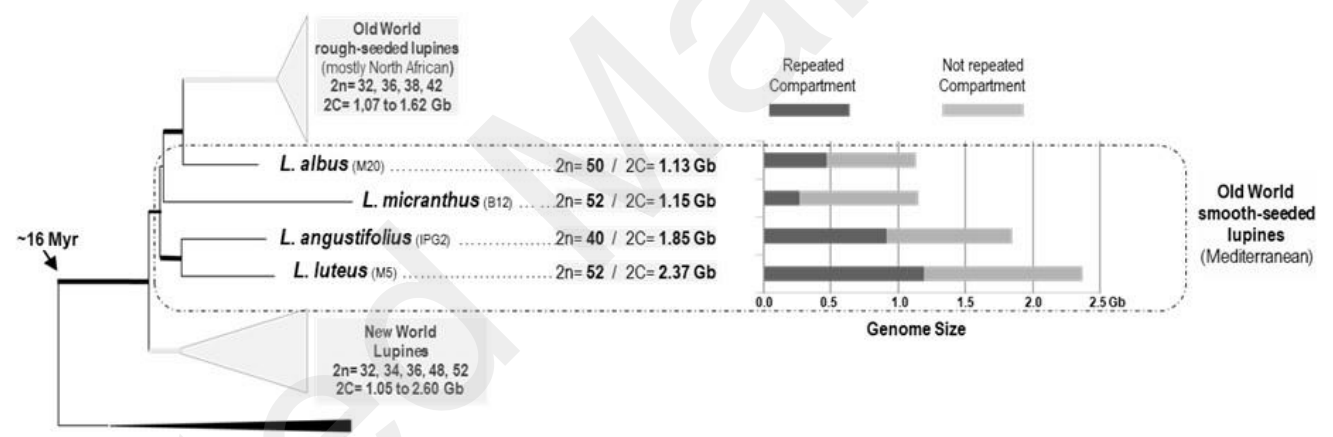

Figure 13.2: Condensed phylogenetic tree of the lupins (on the left) redrawn from

(Mahé et al., 2011), showing the position and relationships of the four Mediterranean smooth-seeded species subjected to a RepeatExplorer analysis of their repetitive genomic compartment. The Old World rough-seeded lupins and the New World lupin clades are presented. The mean age of the lupin stem node is indicated (according to Hughes and Eastwood, 2006). Chromosome numbers (2n) and genome size $(2 \mathrm{C}$ in $\mathrm{Gb})$ of the taxa are given on the right of the figure, together with a histogram showing the genomic proportion of the repeated compartment in the four Mediterranean smooth-seeded species analyzed. 


\subsubsection{Composition of the repetitive compartment in lupin ge- nomes.}

Identification and distribution of the main elements of the repetitive compartment have been determined in the four targeted genomes. As summarized in Table 13.3 and illustrated in Figure 13.2, the repetitive compartment (including transposable elements and tandem repeat satellites; excluding nuclear ribosomal DNA sequences or nrDNA) represents a large part of the genomes and varies from $23.27 \%$ of the small genome of L. micranthus to $50.36 \%$ in the largest genome of L. luteus, regardless of their same chromosome number $(2 n=52)$. While L. albus shares a close chromosomes number $(2 \mathrm{n}=50)$ and a similar genome size with $L$. micranthus, it contains a much larger proportion of repeats (41.10\%). In turn, the accession of Lupinus angustifolius analyzed here, which has a lower chromosome number $(2 \mathrm{n}=40)$, and a relatively large genome $(2 \mathrm{C}=1.85 \mathrm{~Gb})$, exhibits a high repeats proportion $(49,63 \%)$, which is underestimated compared to the 54\% reported for the NLL cultivar Tanjil sequenced genome (Hane et al., 2017).

In L. albus, L. luteus, and L. micranthus, the repetitive compartment is mainly composed of transposable elements, which are essentially represented by variable proportions of LTR retrotransposons $(33,27 \%, 41,10 \%$ and $13,43 \%$ of the genome, respectively), whereas LINEs and DNA transposons are present at less than $2 \%$ in each ge- 
nome (Table 13.3; Figure 13.3). Apart from the indeterminate repeats (around 2 to $3 \%$ ), satellites (tandem repeats) are present at a low proportion in the three genomes, ranging from $3.37 \%$ in $\mathrm{L}$. albus, to $\sim 5-6 \%$ in L. luteus and L. micranthus. Whilst similar repeat categories were detected in L. angustifolius, it exhibited a noteworthy different pattern, with a repetitive compartment made up of a little more than half by satellites (around $26 \%$ of the genome). The remaining part is mainly composed of LTR retrotransposons (approximately $21 \%$ of WG). Although, the RepeatExplorer-based proportion of LTR retrotransposons was lower than that estimated from the NLL (narrow-leafed lupin) sequenced genome ( 28\%), the above observations already demonstrate that not only TEs but also satellites may account for high proportions in lupine genomes where they may reach substantial amounts, ranging from $\sim 38 \mathrm{Mb}$ and $\sim 65 \mathrm{Mb}$ in the small genomes (of L. albus and L. micranthus, respectively) to $\sim 126 \mathrm{Mb}$ and $\sim 481 \mathrm{Mb}$ in the larger genomes of L. luteus and $L$. angustifolius, respectively. Otherwise, the nrDNA varies from 1.5 to $2 \%$ in the genomes of L. albus, L. luteus, and L. micranthus, while it displays a significant increase in L. angustifolius $(\sim 3 \%)$, which suggests the occurrence of different nrDNA evolutionary patterns among the Mediterranean lupins (Wolko and Weeden, 1989; Kroc et al., 2014). 
Table 13.3: Proportions of the main DNA repeats categories (as $\%$ of the genome) in four Old World lupins. Repeats are classified is according to RepeatExplorer annotation

\begin{tabular}{lcrrrr}
\hline \multicolumn{5}{c}{ Genomic proportion of the different DNA repeat categoties } \\
\hline Repeats annotation & $\begin{array}{l}\text { L. } \text { al- } \\
\text { bus }\end{array}$ & $\begin{array}{l}\text { L. angusti- } \\
\text { folius }\end{array}$ & \multicolumn{1}{l}{$\begin{array}{l}\text { L. lu- } \\
\text { teus }\end{array}$} & \multicolumn{2}{l}{$\begin{array}{l}\text { L. micran- } \\
\text { thus }\end{array}$} \\
\hline $\begin{array}{l}\text { LTR retrotransposons (co- } \\
\text { pia+gypsy) }\end{array}$ & $\mathbf{3 3 , 2 7}$ & $\mathbf{2 0 , 4 4}$ & $\mathbf{4 1 , 1 0}$ & $\mathbf{1 3 , 4 3}$ \\
LINE & 0,07 & 0,04 & 0,03 & 0,08 \\
DNA transposons & 1,52 & 1,05 & 1,24 & 0,88 \\
Satellites sensu lato & 3,37 & $\mathbf{2 5 , 9 7}$ & 5,29 & 5,74 \\
Unknown & 2,94 & 2,13 & 2,69 & 3,15 \\
nrDNA/45S & 1,95 & 2,91 & 1,53 & 1,67 \\
\hline Repetitive Compartment (nrDNA & & & & \\
excluded) & $\mathbf{4 1 , 1 8}$ & $\mathbf{4 9 , 6 3}$ & $\mathbf{5 0 , 3 6}$ & $\mathbf{2 3 , 2 7}$ \\
\hline
\end{tabular}

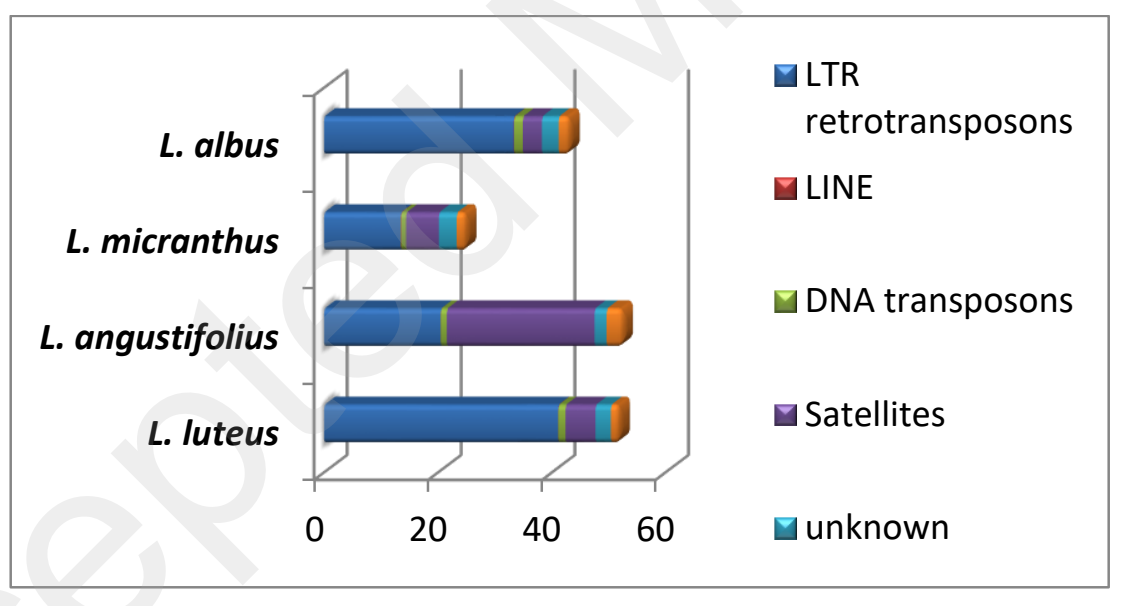

Figure 13.3: Histogram showing the genomic proportions of the main DNA repeats categories (as \% of the genome) in four Old World lupins. Repeats are classified according to RepeatExplorer annotation outputs (Novák et al., 2010). 
13.6.2 Identification and distribution of LTR retrotransposons in the lupin genomes. A more accurate analysis of the repetitive compartment shows that the copia and gypsy superfamilies of LTR retrotransposons are well represented in all species, at various proportions and different relative ratio (Table 13.4; Figure 13.4). Copia elements constitute $5.48 \%(62.9 \mathrm{Mb})$ to $11.73 \%(216.8 \mathrm{Mb})$ of the genomes, with highest proportions in large genomes $(216.8 \mathrm{Mb}$ for L. angustifolius and $231.5 \mathrm{Mb}$ for L. luteus). In turn, the gypsy elements exhibited a wider range, from $3.73 \%(42.8 \mathrm{Mb})$ in the small genome of L. micranthus to $31.31 \%(741 \mathrm{Mb})$ in the largest genome of L. luteus, with however no correlation with GS regarding the substantial proportion of $20.31 \%(230.4 \mathrm{Mb})$ in L. albus (with a small GS) as compared to that of L. angustifolius $(8.7 \% ; 160.8 \mathrm{Mb})$ which has a larger GS. Accordingly, this observation reveals two distribution patterns of the LTR retrotransposon superfamilies. The first one is characterized by a gypsy/copia ratio lower than 1, where copia elements are $~ 1.3-1.5$ times more abundant than the gypsy ones, such as in L. micranthus and L. angustifolius. The second pattern is defined by a gypsy/copia ratio much higher than 1, where gypsy elements clearly represent the prominent part of the LTR elements and are 2.6 and 3.2 times more abundant than the copia ones in L. albus and L. luteus, respectively. 
Table 13.4: Proportions of the LTR-retrotransposon copia and gypsy families (as \% of the genome) detected in four Old World lupins (annotated according to the nomenclature of (Wicker et al., 2007).

\begin{tabular}{|c|c|c|c|c|}
\hline TE Superfamily \& Family & L. albus & L. luteus & L. micranthus & L. angustifolius \\
\hline copia - AleI/Retrofit & 0,09 & 0,03 & 0,07 & 0,03 \\
\hline copia - AleII & 0,05 & 0,38 & 0,17 & 0,09 \\
\hline copia - Angela & 1,13 & 1,41 & 0,92 & 1,49 \\
\hline copia - Ivana/Oryco & 0,21 & 0,42 & 0,09 & 0,22 \\
\hline copia - TAR & 0,44 & 0,50 & 0,37 & 0,54 \\
\hline Copia - Tork & 0,77 & 0,96 & 0,70 & 1,30 \\
\hline copia - Maximus/SIRE & 5,06 & 6,06 & 3,15 & 8,06 \\
\hline $\begin{array}{r}\text { Subtotal copia (\% of the ge- } \\
\text { nome) }\end{array}$ & 7,75 & 9,78 & 5,48 & 11,73 \\
\hline gypsy - Athila & 1,09 & 16,12 & 0,97 & 3,30 \\
\hline gypsy - Ogre/Tat & 0,65 & 4,58 & 1,47 & 1,27 \\
\hline gypsy - Chromovirus & 18,57 & 10,62 & 1,29 & 4,14 \\
\hline $\begin{array}{r}\text { Subtotal gypsy ( \% of the ge- } \\
\text { nome) }\end{array}$ & 20,31 & 31,31 & 3,73 & 8,70 \\
\hline gypsy/copia ratio & 2,62 & 3,2 & 0,68 & 0,74 \\
\hline
\end{tabular}



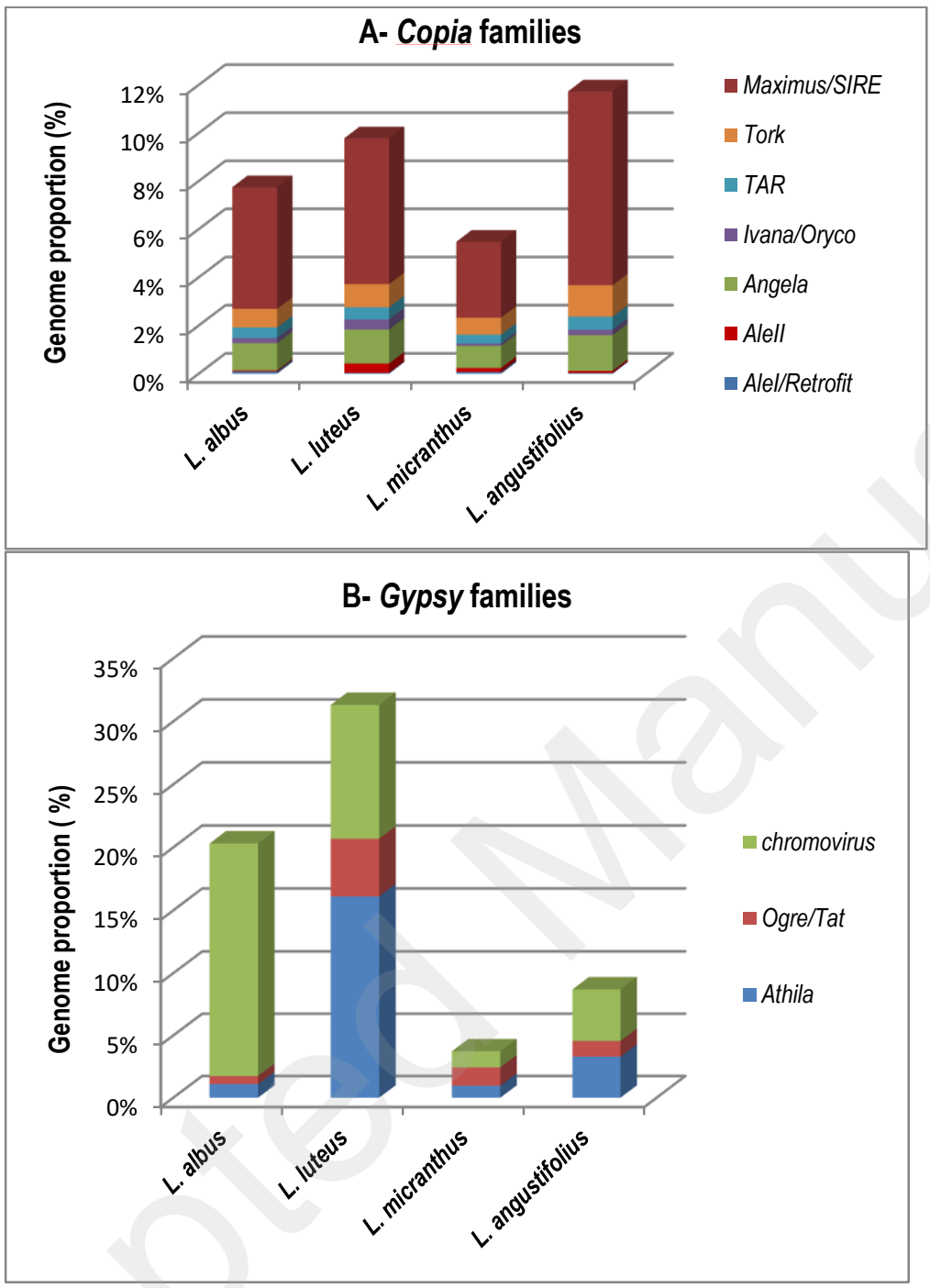

Figure 13.4: Histogram showing the genomic proportions of the LTR-retrotransposon copia (A) and gypsy (B) families (as \% of the genome) detected in four Old World lupines. Retrotransposons are annotated according to the nomenclature of (Wicker et al., 2007). 
A thorough annotation revealed that each of the LTR superfamilies is characterized by a fairly homogeneous and similar profile of copia and gypsy TE families in the lupin genomes surveyed, regardless of their variable proportions. Indeed, seven different copia (Alel/Retrofit, AlelI, Angela, Ivana/Oryco, TAR, Tork, and Maximus/SIRE) and three gypsy (Athila, Ogre/Tat, Chromovirus) families were identified in all species (Table 13.4; Figure 13.4). The Maximus/SIRE family is the best represented in the copia superfamily with 3 to $8.06 \%$ of the genomes (in L. micranthus and L. angustifolius, respectively), followed at a lower level by the Angela (0.92 to $1.49 \%)$ and Tork (0.7 to $1.3 \%)$ families. Together, the latter three families represent 86 to $92 \%$ of the copia elements of each genome, while the remaining families (TAR, Tork, AleI, Allel/Retrofit, Ivana/Oryco) are poorly represented, each at less than $0.6 \%$ of the nuclear genome. In the gypsy superfamily, the Athila family alone represents $16.2 \%(\sim 382 \mathrm{Mb}$, i.e. half of the repetitive compartment) of the large L. luteus genome, whereas the Chromovirus family makes up $10.62(\sim 252 \mathrm{Mb})$ and $18.57 \%(210 \mathrm{Mb})$ of the genomes of L. luteus and L. albus (a small genome). The Ogre/Tat family is much less represented throughout the lupine genomes (less than $5 \%$ ), with however a substantial amount $(4.58 \%$, i.e. $\sim 109 \mathrm{Mb})$ in the large L. luteus genome. It is interesting to notice here: (i) that the amplification of Athila and Chromovirus elements played a decisive role in genome size increase in L. luteus (together representing $26.74 \%$ of the genome) compared to its counterpart L. micranthus $(2.26 \%)$, which has the same chromosome number and a smaller ge- 
nome; (ii) that the latter elements were either only moderately amplified (or amplified then partly deleted via removal mechanisms; (Devos, 2002)), such as in the other large genome of L. angustifolius (7.44\%); but also, (iii) that gypsy elements may significantly proliferate in the small genomes, such as Chromovirus (18.57\%) in L. albus.

\subsubsection{Phylogenetic analysis on LTR retrotransposons $R T$ do- mains.}

In order to refine the annotation of LTR retrotransposons and to get insights into their diversity and dynamics in the Mediterranean lupine genomes, phylogenetic analyses were performed on RT (reverse transcriptase) domains extracted from clusters of reads generated by the RepeatExplorer analyses.

For each species, reads of each cluster (annotated as copia or gypsy) were assembled independently with Mira4 (Chevreux et al., 1999), and the consensus sequences obtained were submitted to BLASTx v. 2.6.0+ (Altschul et al., 1990; Camacho et al., 2009) against a public database of RT nucleotide sequences (Repbase v. 23.08; (Bao et al., 2015)). Sequences translated in protein which showed homology with RT domains, and that have at least 130 amino acids in length, were kept for further analyses. RT sequences from six angiosperms species (Glycine max, Medicago truncatula, Arabidopsis thaliana, Zea mays, Oryza sativa, Triticum monococcum) were selected in Repbase and added to the dataset. Only potentially functional se- 
quences without stop codon were retained. Each of the gypsy or copia RT protein sequences were aligned separately using Clustal Omega (Sievers et al., 2014). Informative blocks in multiple alignment were selected with the GBlocks package (Castresana, 2000) prior to perform phylogenetic analyses with IQ-TREE (Nguyen et $a l ., 2015)$. The LG+R6 and the LG+R7 protein evolution models were respectively retained (via ModelFinder; (Kalyaanamoorthy et $a l ., 2017)$ for phylogenetic reconstruction of gypsy and copia trees using the maximum likelihood method. The robustness of branches was estimated after 10,000 Ultrafast Bootstraps (Hoang et al., 2017). Annotation of copia and gypsy elements was determined according to the classification of Wicker et al., 2007.

The copia tree was built with 71 lupin sequences (43 from $L$. angustifolius, 2 from L. micranthus, 13 from L. albus and 13 from $L$. luteus) and 244 sequences from other taxa (Figure 13.5). Interestingly, all the most conserved RT sequences detected in L. albus, L. luteus and L. micranthus, and about half of those detected L. angustifolius, belong to the Maximus/SIRE family, which agrees with the prominence of this copia family in the lupin genomes. Moreover, this suggests that these elements, displaying well conserved RT domains, most likely result from recent amplification events experienced by each species, as this seems corroborated by some specific groups of poorly divergent sequences with short branches (indicated in Figure 13.5). All the other remaining conserved RT sequences represented diverse Angela, TAR, Tork and Ale elements detected in 
L. angustifolius, which indicates that it is the only Mediterranean lupine species containing conserved copies of these copia families that are potentially able to proliferate. In particular, a distinct monophyletic group of Angela RTs suggests a lineage-specific amplification of one Angela line during the recent evolutionary history of this species. Although, AleII/Retrofit and Ivana/Oryco elements were detected in all lupins, indicating their common and ancient origin, no conserved RTs were found, which suggests that these poorly represented elements have undergone degenerative processes that tend towards their elimination from the genomes. 


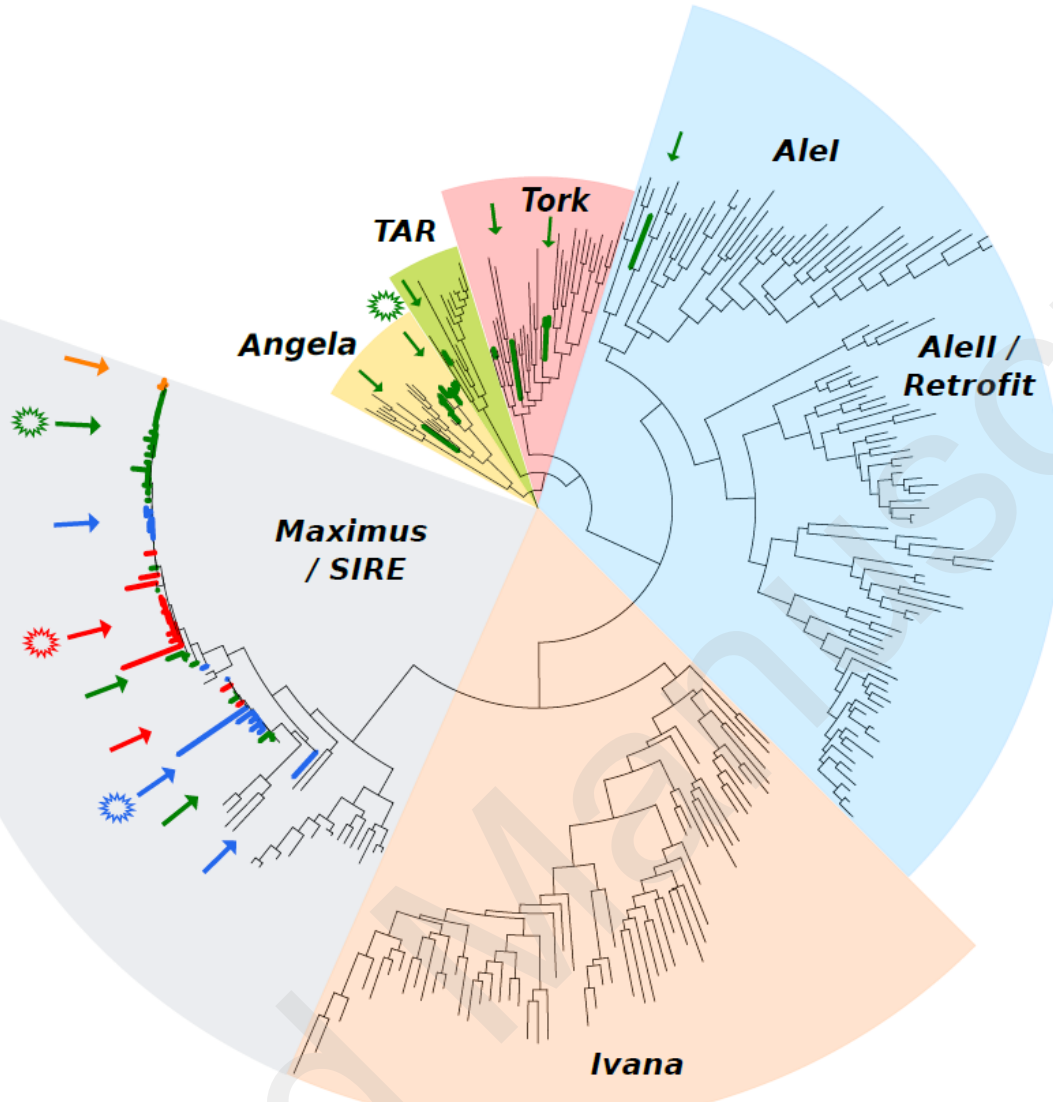

Figure 13.5: Phylogenetic analysis of lupin LTR-retrotransposon copia elements based on amino-acid sequences of their conserved RT domains, using the maximum likelihood method. The tree was built with 71 lupin sequences (43 from $L$. angustifolius, 2 from L. micranthus, 13 from L. albus and 13 from L. luteus) and 244 reference sequences from databases. Annotation of copia families (colored clades named in black and bold) were determined following the classification of (Wicker et al., 2007). Each terminal branch is colored according to its species origin: green for $L$. angustifolius, orange for L. micranthus, blue for L. albus, red for L. luteus, and black for reference taxa. Radiated/irregular circles likely represent recent species-specific amplification of particular copia lines. 
The gypsy tree was constructed with 72 lupine sequences (7 from $L$. angustifolius, 1 from L. micranthus, 29 from L. albus and 35 from $L$. luteus) and 236 reference sequences from a set of plant genomes (Figure 13.6). All the most conserved RT sequences detected belong to the three gypsy families identified via RepeatExplorer, Chromovirus, Athila and Ogre/Tat (Table 13.4). The distribution of the conserved RTs among species appears correlated with the relative proportions of the gypsy families in the genomes. Conserved RTs of Athila elements were mostly found in L. luteus (13) and few in $L$. angustifolius (3) and L. albus (1). Few conserved RTs (1 to 3 ) of the Ogre/Tat elements were detected in lupins (with none in L. albus). With regard to Chromovirus elements, conserved RTs were mostly extracted from L. luteus and L. albus, the richest genomes in gypsy elements, and only three from L. angustifolius. Among the wide range of known Chromovirus elements, the phylogeny allowed to refine the classification of the lupin ones into two subfamilies, most of them as Tekay homologs and the few others as CRM homologs (following RepBase annotation). Interestingly, the gypsy phylogeny reveals that $L$. luteus and L. albus most likely experienced recently independent and specific proliferation of gypsy elements, as this is illustrated by noteworthy monophyletic and monochromatic groups of poorly divergent RTs (with short branches) of Tekay and Athila retrotransposon lineages in Figure 13.6. The other conserved RTs are minority lineages of gypsy elements represented in the Mediterranean lupin genomes that seem, however, yet potentially functional and able to proliferate. 


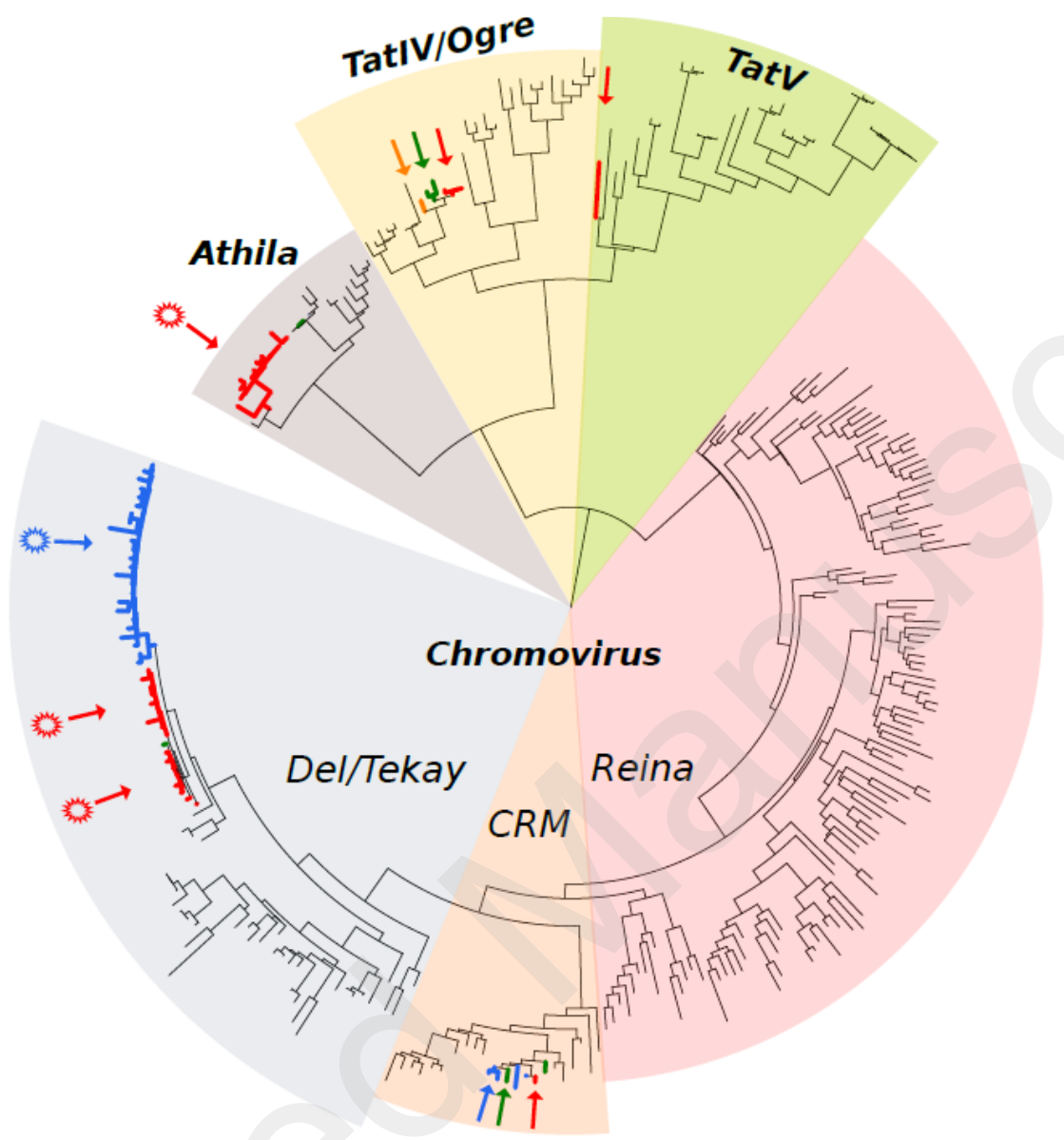

Figure 13.6: Phylogenetic analysis of lupin LTR-retrotransposon gypsy elements based on amino-acid sequences of their conserved RT domains, using the maximum likelihood method. The tree was built with 72 lupin sequences (7 from $L$. angustifolius, 1 from L. micranthus, 29 from L. albus and 35 from L. luteus) and 236 reference sequences from databases. Annotation of gypsy families (colored clades named in black and bold) were determined following the classification of (Wicker et al., 2007). Each terminal branch is colored according to its species origin: green for L. angustifolius, orange for L. micranthus, blue for L. albus, red for L. luteus, and black for reference taxa. Radiated/irregular circles likely represent recent species-specific amplification of particular gypsy lines. 


\subsubsection{Diversity and abundance of Tandem Repeats in lupin ge-} nomes

As shown from the above RepeatExplorer-based analysis, the proportion of tandem repeats (excluding nrDNA) in the Mediterranean lupin genomes, varies from $3.37 \%$ in L. albus to a tremendous value of $26 \%$ in L. angustifolius (Table 13.3). In the latter species, TRs were even revealed more abundant than TEs. For each species, the reads contained in the clusters annotated as TRs were together analyzed using the TRF program v.4.09 (Tandem Repeat Finder; (Benson, 1999)) in order to identify the TR motives (k-mers < 50bp) and their statistical distribution. Among the best represented SSRs (with k-mer motives < 10bp), three k-mers (AGGAT, GATGAG and GTTTAGG) were almost always present at a low level (less than $0.6 \%$ ) in the four genomes, with however an exceptional accumulation of the 6-mer GATGAG estimated at $15.24 \%$ of the genome in L. angustifolius. (Table 13.5; Figure 13.7). Tandem repeats with kmers $>10 b p$ may constitute substantial amounts in lupin genomes and represent the main TR fraction in L. albus (1.64\%) and L. luteus (2.78\%). Interestingly, complementary analyses of the latter TR fraction (using TAREAN program; (Novák et al., 2017)) allowed identification of one major 28-mer minisatellite in L. luteus, one major 170-mer satellite and one 38-mer minisatellite in L. albus, as well as two 165-mer and 629-mer satellites in L. micranthus. 
Table 13.5: Proportion of the main types of tandem repeats (as $\%$ of the genome) detected in four Old World lupins.

\begin{tabular}{lrrrr}
\hline TR motifs & L.albus & L. angustifolius & L. luteus & L. micranthus \\
\hline AGGAT (5 bp) & 0,16 & 0,33 & 0,37 & 0,60 \\
GATGAG (6 bp) & 0,00 & 15,24 & 0,25 & 0,57 \\
GTTTAGG (7 bp) & 0,13 & 0,16 & 0,06 & 0,20 \\
Others < =10 bp & 0,20 & 0,93 & 0,06 & 0,19 \\
Others >10 bp & 1,64 & 2,26 & 2,78 & 0,53 \\
\hline
\end{tabular}

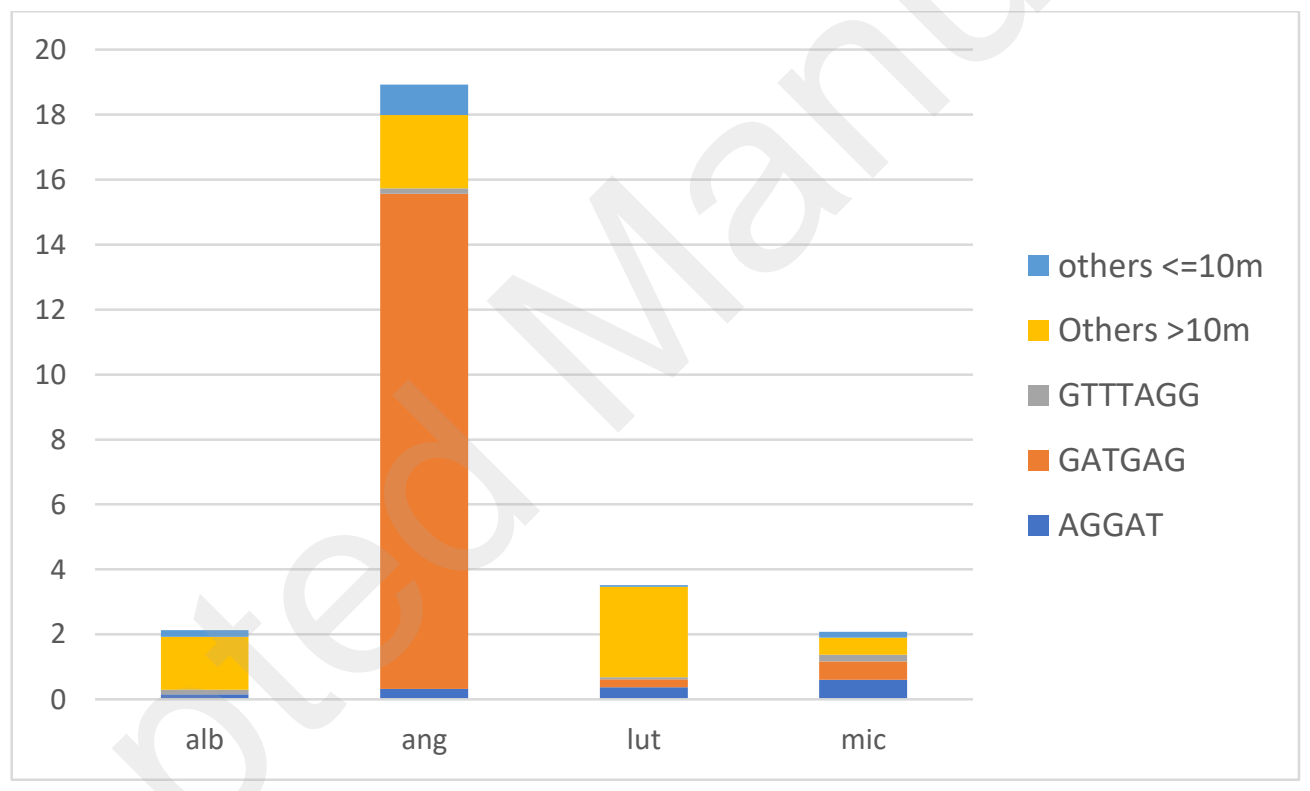

Figure 13.7: Histogram representing the diversity and proportion of the simple sequence repeats (as \% of the genome) detected in four Old World lupins using Tandem Repeat Finder program (Benson, 1999; Lim et al., 2013): from L. albus(alb), L. angustifolius (ang), L. luteus (lut), and L. micranthus (mic). 
Moreover, taking advantage of the availability of a reference genome (L. angustifolius NLL cultivar. Tanjil; (Hane et al., 2017)), the twenty annotated pseudochromosomes were screened with TRF in order to identify, localize and estimate the distribution of microsatellites (as per cent of 100-kb). Almost all tandem repeats found in coding sequences are 2- or 3-mers, of which the 3-mer "CTT" is the most commonly distributed. However, they only represent a total of 24,000 bp (i.e, $0.03 \%$ of the assembled genome). Interestingly, the presence of the other abundant SSRs (5-, 6- and 7-mers) detected above in our L. angustifolius accession (IPG2 from Morocco) were confirmed in the Tanjil genome, but were rather localized outside of the coding sequences. The density and localization of the SSRs relative to the distribution of the genes are summarized in Figure 13.8 (using a Circos representation; (Krzywinski et al., 2009)). The SSRs are distributed in all the genome and didn't exhibit any chromosome specificity. The 6-mer SSR(GATGAG) $)^{\mathrm{n}}$ previously identified in the IPG2 accession is confirmed as the major SSR in the NLL genome cv. Tanjil, with pics of density mainly distributed in gene-poor regions. A thorough survey reveals that 1,143 genes include SSRs with the 3-mer (CTT) repeated at least four times. For example, a microsatellite with 65 perfect tandemly repeated (CTT) monomers was found in a putatively functional gene encoding a cytosolic oligopeptidase (ID:109349122). 


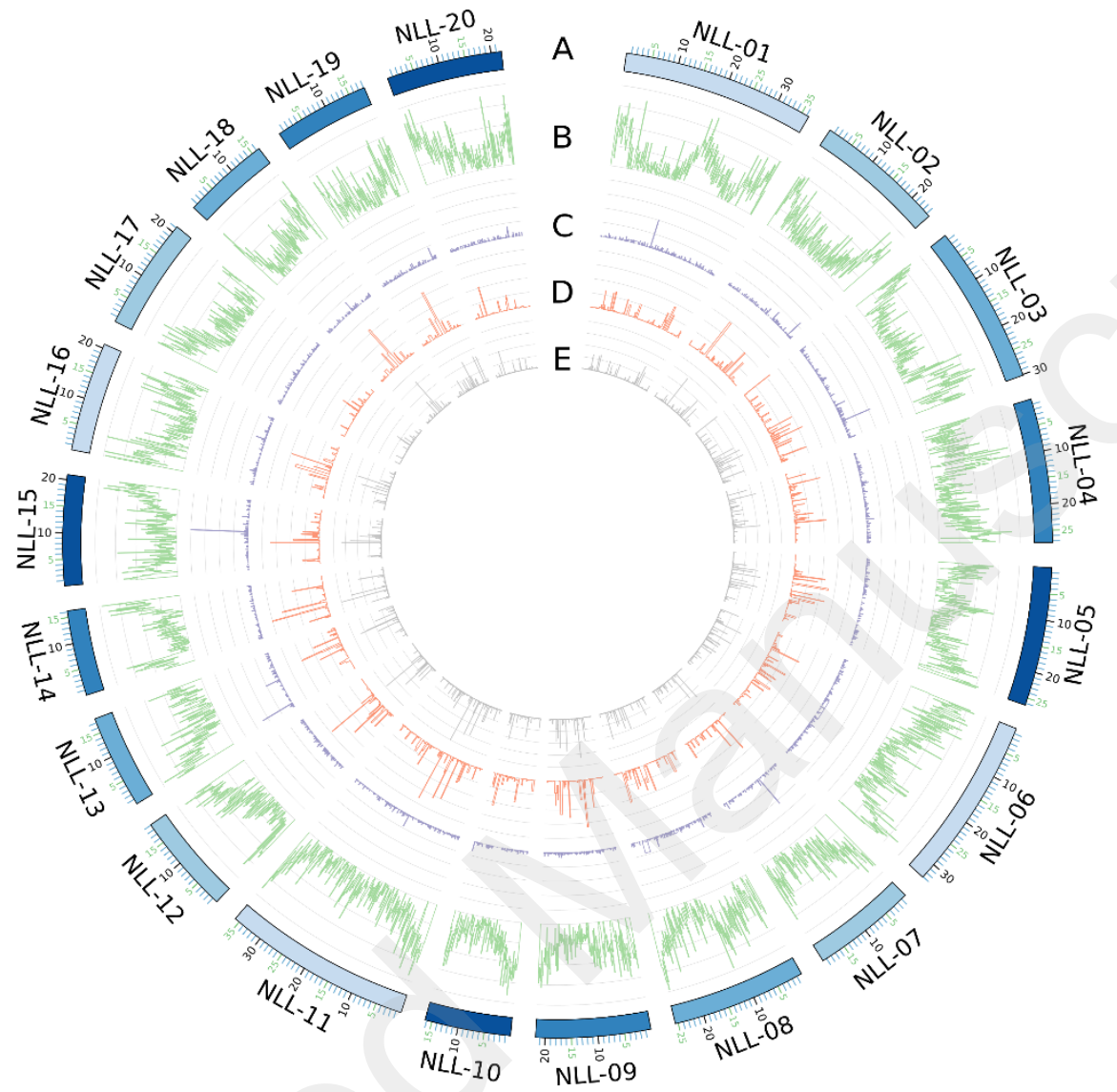

Figure 13.8: Microsatellites distribution along pseudochromosomes of the first WG lupin sequenced, L. angustifolius (NLL var. Tanjil). The five consecutive circles from the outside to the inside of the figure represent: A, the 20 chromosomes (named NLL-01 to NLL-20) (in blue); B, Genes distribution and proportions per $100 \mathrm{~kb}$ (in green); C, proportions per $100 \mathrm{~Kb}$ of the 3 -mer SSRs (CTT) ${ }^{\mathrm{n}}$ (x10 to be readable; in mauve); proportions per $100 \mathrm{~Kb}$ of 6-mers SSRs (in orange); and proportions per $100 \mathrm{~Kb}$ of all microsatellites (in grey). The higher the peaks are the higher is the proportion of genes or SSRs 


\subsection{Repetitive compartment of lupin genomes}

In this chapter, we present the first detailed evaluation of the repetitive compartment in genomes of four smooth-seeded Mediterranean lupin taxa, based on the analysis of low-depth NGS genomic resources, using various bioinformatics programs to identify and estimate the repetitive sequences (Benson, 1999; Novák et al., 2010, 2017; Novak et al., 2013). This approach already proved its usefulness to detect and to evaluate repeats in several taxa, which represent at least $0.01 \%$ of the genome, based on a genome coverage of $>0.5 \%$ (Pisum sativum, (Macas et al., 2007); Musa acuminata, (Hřibová et al., 2010); Nicotiana tabacum, (Renny-Byfield et al., 2011) ; Orobanchacea, (Piednoël et al., 2013); Genlisea, (Vu et al., 2015). Our estimate of the repetitive DNA in one accession of L. angustifolius (IPG2), based on a reduced sample of randomly selected reads $(1 \mathrm{C}$ genome coverage $=3.25 \%)$ following the RepeatExplorer strategy, resulted in a proportion of $52.54 \%$ (including nrDNA) which is fairly close to the proportion of $57 \%$ found in the whole genome sequenced of the NLL cultivar Tanjil (Hane et al., 2017). Also this was underlined by the studies cited above, which supports the robustness and reliability of this approach to investigate and compare non model species. Accordingly, this study yielded major information and insights on the composition, characterization, distribution and dynamics of the repetitive sequences in lupin genomes. 


\subsubsection{The repetitive compartment represents a significant frac-} tion of lupin genomes

As frequently observed in other angiosperms (Bennetzen, 2000, 2005; Piegu et al., 2006; Hu et al., 2011; Bennetzen \& Wang, 2014; Vu et al., 2015; Wendel et al., 2016), the repetitive compartment represents a large proportion of the genomes (23 to 51\%, excluding nrDNA) in the Mediterranean smooth-seeded lupins. The highest proportions were found in the largest genomes, regardless of their chromosome number, $50.36 \%$ in L. luteus $(2 n=52 ; 2 \mathrm{C}=2.37 \mathrm{~Gb})$ and $49.63 \%$ in L.angustifolius $(2 n=40 ; 2 \mathrm{C}=1.85 \mathrm{~Gb})$, whereas the two lupins with small genomes and fairly similar chromosome numbers exhibited very contrasted proportions of repeats in their genomes, $23.27 \%$ in L. micranthus $(2 n=52 ; 2 \mathrm{C}=1.15 \mathrm{~Gb})$ versus $41.10 \%$ in $L$. albus $(2 n=50 ; 2 \mathrm{C}=1.13 \mathrm{~Gb})$. Therefore, the proportion of the repetitive compartment in the smooth-seeded Mediterranean lupins is overall neither correlated to chromosome numbers nor to GS, although large genomes are associated with a strong accumulation of repeated sequences (but not only, regarding the example of L. albus).

\subsubsection{Gypsy and copia retrotransposons significantly contribute} to genome size variation.

The repetitive compartment is mainly composed of transposable elements ( $\sim 33$ to $\sim 85 \%)$ in the lupins surveyed and they significantly 
contribute to the variation of their genome size. Moreover, the overwhelming majority of TEs is composed of Class I gypsy and copia LTR-retrotransposons (ranging from $93.9 \%$ of TEs in L. micranthus to $97 \%$ in L. luteus), which in fine are the main repeats fraction involved in GS differences (but see later). Together the other Class I (such as LINEs) and Class II elements (DNA transposons) only represented a minor fraction of the lupin genomes (less than 1.6\%). This is in general accordance with estimates from other angiosperms, albeit some taxa exhibited a much higher proportion of Class II elements (11 to $16.5 \%$ ), such as in A. thaliana, G. max, wheat and rice (Hawkins et al., 2006; Oliver et al., 2013).

The analyses based on random amplified RT domains and on Illumina HiSeq sequence data sets revealed in both lupin and Genistoid genomes a wide diversity of shared copia and gypsy LTRretrotransposons families. The thorough evaluation of LTRretrotransposon elements (via the RepeatExplorer strategy) highlighted the occurrence of a typical general profile of copia and gypsy families and subfamilies in the smooth-seeded Mediterranean lupin genomes, each species displaying its specific profile characterized by its own relative proportions of these elements. Additionally, a remarkable difference in the gypsy/copia ratio was observed among these species, regardless of their genome size as well as of their phylogenetic relationships, which is well exemplified by the prevalence of copia elements ( 1.4 times more than gypsy) in L. micranthus and L. angustifolius and conversely by the over-accumulation of gypsy 
elements (2.6 to 3.2 times more than copia) in L. albus and L. luteus. It is noteworthy that few individual gypsy (Chromovirus and Athila) and copia (Maximus-SIRE) families alone have been remarkably accumulated in the lupins and hence strongly contributed in shaping their LTR-retrotransposon profiles and in their GS differences, as shown in L. luteus (26.74\% of Athila + Chromovirus), L. micranthus (18.57\% of Chromovirus) and L. angustifolius (12.2\% of Maximus/SIRE + Chromovirus).

\subsubsection{Evolutionary considerations on the dynamics of transpos- able elements in lupins.}

Altogether the above observations provide interesting insights on the dynamics of the repetitive sequences in lupin genomes, particularly of their major component, LTR-retrotransposon elements. Overall, the same types of elements have been retrieved in both lupins and Genistoids (Mahé, 2009), which supports their ancient origin from the common ancestor of the Genistoid alliance (and earlier). Nevertheless, it is obvious that the lupin genomes experienced divergent evolutionary dynamics, as demonstrated by the remarkable variability of the species-specific profiles of elements observed among the few representatives of the closely related Old World lupins investigated. Some LTR retrotransposon families appear to have actively proliferated and accumulated in some species (e.g., Athila, Chomovirus, Maximus-SIRE elements, or even Ogre/Tat) while they 
have been maintained at a low level in others. Most other families remained poorly represented throughout species. This strongly suggests that different processes and mechanisms regulating amplification, proliferation and clearance of these repeats (Lippman et al., 2004; Ma \& Bennetzen, 2004; Hawkins et al., 2006, 2009; Slotkin \& Martienssen, 2007; Lisch, 2009; Yaakov \& Kashkush, 2012) have differentially operated in these species over the last $\sim 10$ Myr of their diversification. This was also shown in other plant systems (e.g.: (Hawkins et al., 2006; Charles et al., 2008; Hu et al., 2011; Estep et al., 2013; Piednoël et al., 2013).

Accordingly, phylogenetic analyses of the most conserved RT sequences (which presumably represent the most recent and potentially yet functional LTR retrotransposons) provided substantial clues which support recent (after species divergence, likely $<8-10 \mathrm{Myr}$ ) and independent amplifications and accumulations (bursts) of the major gypsy and copia elements (Athila, Chomovirus, MaximusSIRE and even Ogre/Tat) in the lupin genomes. The other less common retrotransposons (such as Angela, TAR, Tork and Ale), which seem still potentially able to proliferate in L. angustifolius, would represent families that either have low transposition rates or that have been specifically subjected to rapid purging processes following their expansion (Ma \& Bennetzen, 2004; Bennetzen, 2005; Hu et al., 2011; Renny-Byfield et al., 2014; Vu et al., 2015). This leaves open the way to different evolutionary trajectories for the later families. Moreover, some weakly represented copia families, such as 
AleII/Retrofit and Ivana/Oryco, seem to have lost their ability to transpose. The yet recognizable but degenerated RTs found for these elements would likely represent the witnesses of ancient transposition events experienced by these families, which are ultimately prone to be erased from the DNA repetitive compartment of the smooth-seeded Mediterranean lupins. Another important evolutionary insight derived from the phylogenetic analysis of conserved RTs is that, not only various LTR retrotransposons families or subfamilies have been differentially accumulated among the different lupin species, but also that particular lineages of these families or subfamilies have been differentially amplified within each species, leading to the emergence of species-specific lineages of elements. For example, the major repeats in L. luteus essentially result from the recent proliferation of three species-specific gypsy lines (one from the Athila family, and two from the Tekay subfamily). Similarly, the prominent fraction of gypsy elements in L. albus results from the massive amplification of another specific lineage of the Tekay subfamily. Also, there are some evidence of likely recent lineagespecific amplification of Maximus-SIRE and Athila elements in $L$. angustifolius. Besides, a quick screening (results not shown) of available raw transcriptomic data sets from roots of L. albus, L. luteus and L. mariae-josephae (Keller et al., 2018) provided some clues indicating a transcriptional activity for various TEs (including for some weakly represented families and ClassII elements). However, deeper investigations of more complete transcriptomic data sets are needed before making any reliable conclusion. 


\subsubsection{Tandem repeats may also greatly contribute to genome obesity and dynamics in lupins.}

In the Mediterranean lupin genomes, the proportion of tandem repeats (excluding nrDNA) remarkably varies from 3 to $6 \%$ in $L$. albus, L. luteus and L. micranthus, to $26 \%$ in L. angustifolius. In contrast to the three former lupins and to the general trend in plants (Oliveira et al., 2006; Barghini et al., 2014; Heitkam et al., 2015; Satovic et al., 2018), the proportion of tandem repeats is not only tremendous, but also is higher than that of transposable elements and represents more than half of the repetitive compartment in $L$. angustifolius. Also, it is noteworthy that even a low proportion of TRs may constitute a substantial fraction, equivalent to $\sim 125 \mathrm{Mb}$ in the large genome of L. luteus, for example. Among the best represented SSRs in the smooth-seeded Mediterranean lupins, three were almost always detected in the genomes (AGGATn, GATGAGn and GTTTAGGn). This is in agreement with the so-called "library hypothesis" evolution model which predicts that closely related species inherit from a common ancestor a same pool of satellites that are then independently amplified or lost in genomes (Fry \& Salser, 1977; Oliveira et al., 2006; Plohl et al., 2012; Garrido-Ramos, 2017). Accordingly, our results revealed different SSR patterns which reflect the differential evolutionary dynamics experienced by these repeats in the lupin genomes. This is particularly well illustrated by the TR profile of $L$. angustifolius. In the latter species, the mi- 
crosatellites $k$-mer $<10 \mathrm{bp}$ ) have been much more accumulated $(16.66 \%)$ than TRs with $k$-mers $>10 \mathrm{bp}(2.26 \%)$ in the genome, compared to its close Mediterranean relatives and to the lower frequencies reported for most other plants surveyed in the literature (Oliveira et al., 2006; Barghini et al., 2014; Heitkam et al., 2015; Satović et al., 2018). Even more striking, only one SSR (the 6-mer $\mathrm{GATGAG}^{\mathrm{n}}$ ) has been highly amplified and accumulated in L. angustifolius (estimated at $15.24 \%$ of the genome), whereas it is maintained at less than $0.6 \%$ in L. luteus and L. micranthus, and seem to have been erased from L. albus. Such contrasted frequencies of particular SSRs among genomes could be partially explained by divergences in the DNA repair system, as suggested by Oliveira et al., (2006).

Alternatively, while SSRs are yet mostly ubiquitous in the smoothseeded Mediterranean lupins (regardless of their various proportions), few distinct families of minisatellites and satellites have been each differentially and specifically amplified in either L. albus, L. luteus or L. micranthus. This suggests that they most likely results from dynamic and complex molecular processes and mechanisms that operated in the repetitive compartment following the diversification of the smooth-seeded Mediterranean lupins, which yielded species-specific satellite families (see: (Garrido-Ramos, 2015; Ávila Robledillo et al., 2018). It has been suggested that differences in satellites types and abundance would play a role in speciation through the establishment of reproductive barriers between species, as 
demonstrated in Drosophila (Ferree \& Barbash, 2009). It is likely that the dramatic expansion of some satellites (alone and/or in conjunction with transposable elements) contributed to isolation and speciation processes among the Mediterranean lupins, as could be suggested by the striking divergent evolutionary dynamics observed following the separation of the closely related L. luteus $(2 n=52$; which preferentially accumulated a specific minisatellite and gypsy element) and L. angustifolius $(2 n=42$; which rather accumulated a remarkable amount of a particular hexamer SSR and copia elements). Additionally, these species-specific satellites represent an important basis for the development of cytogenetic markers to identify chromosomes, and to help understanding genome organization in lupins.

Another interesting observation highlighted from the screening of the available reference genome of $L$. angustifolius (NLL cv. Tanjil) is that all satellites sensu lato detected in our NLL accession (IPG2) were retrieved throughout all the twenty pseudochromosomes. Two different distribution patterns were observed. On one side, almost all the 5-, 6- and 7-mer SSRs observed in IPG2 are localized outside of the coding sequences in the gene-poor regions, with (GATGAG)n confirmed as the major SSR in this species. On the other side, the tandem repeats found in the coding regions are almost all SSRs with short monomers $(k$-mer $<4 \mathrm{bp})$, of which the SSR $(\mathrm{CTT})^{\mathrm{n}}$ is the most abundant and widespread throughout the pseudochromosomes. Such prevalence of trinucleotide SSRs in the coding regions indicate that 
the other types with larger k-mers, which have a greater likelihood to induce frameshift mutations, are subjected to a counter-selection (Metzgar et al., 2000; Toth, 2000). The screening of the NLL cv. Tanjil genome identified 1143 genes which contain a (CTT)n SSR with n equal to or greater than 4 , which raises important questions to be addressed in order to evaluate their molecular, functional and evolutionary impact.

\subsection{Conclusion and perspectives}

This paper represents the first study on the repetitive compartment in lupin genomes, using low-depth high-throughput sequencing, reads clustering and annotation. The detailed analyses performed in four smooth-seeded Mediterranean lupins revealed a wide diversity of repeat types and allowed identification of the most abundant categories involved in shaping their genomes. In particular, only few gypsy (Tekay, Athila, Ogre) and copia (Maximus-SIRE) LTR retrotransposon families make up the prominent fraction of the repeats, which significantly contributes to genome size variation among species, regardless of their chromosome numbers and phylogenetic relationships. Interestingly, the results revealed that, not only retrotransposons, but also tandem repeats, such as microsatellites, may greatly contribute to genome obesity and dynamics in lupins, as demonstrated in L. angustifolius. Additionally, it has been shown that differential lineage-specific accumulation of transposable elements and/or tandem repeats occurred in lupins, which strongly supports that different processes and mechanisms regulating amplification, prolifera- 
tion and clearance of repeats have differentially operated within the same genus and among closely related Mediterranean species over the last $~ 10-12 \mathrm{Myr}$.

Further extension of such evaluation to representatives of the different lupin clades circumscribed in the genus will undoubtedly provide a more accurate and enhanced overview of the repetitive components and their evolutionary dynamics following diversification, evolution and adaptation to diverse environmental conditions in both the Old and the New World. Additionally, the annotated raw material generated by this work represents a valuable basis to start building a repeats database specifically dedicated to the genus: (i) to accompany and facilitate assembly and annotation of novel lupin genomes; and (ii) to develop potentially useful genetic (e.g., microsatellites) and cytogenetic markers (e.g., specific minisatellites, satellites and TEs). This will help understanding structure, organization, repeats distribution and localization), variability, and evolution of the genomic landscape of lupins, and will enable comparative analysis with other legumes. Furthermore, the development of such database of repeats, using and combining genomic resources from both rapid low-depth high-throughput sequencing of various taxa and deep WGS of targeted species or accessions of particular interest, are of great importance to investigate and evaluate their structural, functional and evolutionary impact on genes, such as, for example, those responsive for important agronomical, adaptive and defense features. 


\title{
Acknowledgements:
}

We are grateful to INEE-CNRS (France) and to the University of Rennes for their support to this work as part of the research program of the International Associated Laboratory "Ecological Genomics of Polyploidy" involving the University of Rennes (France) and the Iowa State University (Ames, USA). We thank Prof. Barbara Naganowska (Institut of Plant Genetics/PAS, Poznan, Poland) for kindly providing L. angustifolius seeds (IPG2 accession).

\section{REFERENCES}

\begin{abstract}
Aïnouche A, Bayer RJ. 1999. Phylogenetic relationships in Lupinus (Fabaceae: Papilionoideae) based on internal transcribed spacer sequences (ITS) of nuclear ribosomal DNA. American Journal of Botany 86(4): 590-607.
\end{abstract}

\begin{abstract}
Ainouche A, Bayer RJ, Misset M-T. 2004. Molecular phylogeny, diversification and character evolution in Lupinus (Fabaceae) with special attention to Mediterranean and African lupines. Plant Systematics and Evolution 246 (3-4), 211-222.
\end{abstract}

Alix K, Heslop-harrison JS. 2004. The diversity of retroelements in diploid and allotetraploid Brassica species. Plant Molecular Biology 54: 895-909.

Altschul SF, Gish W, Miller W, Myers EW, Lipman DJ. 1990. Basic local alignment search tool. Journal of Molecular Biology 215: 403-410.

Atnaf M, Yao N, Martina K, Dagne K, Wegary D, Tesfaye K. 2017. Molecular genetic diversity and population structureof Ethiopian white lupin landraces: Implicationsfor breeding and conservation. PLOS ONE 12(11):e0188696.

Ávila Robledillo L, Koblížková A, Novák P, Böttinger K, Vrbová I, Neumann P, Schubert I, Macas J. 2018. Satellite DNA in Vicia faba is characterized by remarkable diversity in its sequence composition, association with centromeres, and replication timing. Scientific Reports 8:5838.

Axtell MJ. 2013. Classification and comparison of small RNAs from plants. Annual Review of Plant Biology 64: 137-159.

Bao W, Kojima KK, Kohany O. 2015. Repbase Update, a database of repetitive elements in eukaryotic genomes. Mobile DNA 6.

Barghini E, Natali L, Cossu RM, Giordani T, Pindo M, Cattonaro F, Scalabrin S, Velasco R, Morgante M, Cavallini A. 2014. The peculiar landscape of repetitive sequences in the olive (Olea europaea L.) genome. Genome Biology and Evolution 6: 776-791.

Bennett MD. 2005. Nuclear DNA Amounts in Angiosperms: Progress, Problems and Prospects. Annals of Botany 95: 45-90. 
Bennetzen JL. 2000. Transposable element contributions to plant gene and genome evolution. Plant Molecular Biology 42: 251-269.

Bennetzen JL. 2002. Mechanisms and rates of genome expansion and contraction in flowering plants. Genetica 115: 29-36.

Bennetzen JL. 2005. Transposable elements, gene creation and genome rearrangement in flowering plants. Current Opinion in Genetics \& Development 15: 621-627.

Bennetzen JL, Wang H. 2014. The contributions of transposable elements to the structure, function, and evolution of plant genomes. Annual Review of Plant Biology 65: 505-530.

Benson G. 1999. Tandem repeats finder: a program to analyze DNA sequences. Nucleic Acids Research 27: 573-580.

Biémont C, Vieira C. 2006. Genetics: Junk DNA as an evolutionary force. Nature 443: 521-524

Biscotti MA, Olmo E, Heslop-Harrison JS. 2015. Repetitive DNA in eukaryotic genomes. Chromosome Research 23(3): 415-420.

Cabello-Hurtado F, Keller J, Ley J, Sanchez-Lucas R, Jorrín-Novo JV, Aïnouche A. 2016. Proteomics for exploiting diversity of lupin seed storage proteins and their use as nutraceuticals for health and welfare. Journal of Proteomics 143: 57-68.

Camacho C, Coulouris G, Avagyan V, Ma N, Papadopoulos J, Bealer K, Madden TL. 2009. BLAST+ architecture and applications. BMC Bioinformatics 10: 421.

Castel SE, Martienssen RA. 2013. RNA interference in the nucleus: roles for small RNAs in transcription, epigenetics and beyond. Nature Reviews Genetics 14: 100-112.

Castresana J. 2000. Selection of Conserved Blocks from Multiple Alignments for Their Use in Phylogenetic Analysis. Molecular Biology and Evolution 17: 540-552.

Charles M, Belcram H, Just J, Huneau C, Viollet A, Couloux A, Segurens B, Carter M, Huteau V, Coriton O, et al. 2008. Dynamics and Differential Proliferation of Transposable Elements During the Evolution of the B and A Genomes of Wheat. Genetics 180: 1071-1086.

Chénais B, Caruso A, Hiard S, Casse N. 2012. The impact of transposable elements on eukaryotic genomes: From genome size increase to genetic adaptation to stressful environments. Gene 509: 7-15.

Chevreux B, Wetter T, Suhai S. 1999. Genome Sequence Assembly Using Trace Signals and Additional Sequence Information. Computer Science and Biology: Proceedings of the German Conference on Bioinformatics 99: 45-56.

Conterato IF, Schifino-Wittmann MT. 2006. New chromosome numbers, meiotic behaviour and pollen fertility in American taxa of Lupinus (Leguminosae): contributions to taxonomic and evolutionary studies. Botanical Journal of the Linnean Society 150: 229-240.

Devos KM. 2002. Genome Size Reduction through Illegitimate Recombination Counteracts Genome Expansion in Arabidopsis. Genome Research 12: 1075-1079.

Dolezel J, Bartos J, Voglmayr H, Greilhuber J. 2003. Nuclear DNA content and genome size of trout and human. Cytometry 51A: 127-128. 
Doolittle WF, Sapienza C. 1980. Selfish genes, the phenotype paradigm and genome evolution. Nature 284: 601-603.

Eastwood RJ, Drummond CS, Schifino-Wittmann MT, Hughes CE. 2008. Diversity and evolutionary history of lupins-insights from new phylogenies. Lupins for health and wealth: 12th International Lupin Conference: 10.

Estep MC, DeBarry JD, Bennetzen JL. 2013. The dynamics of LTR retrotransposon accumulation across 25 million years of panicoid grass evolution. Heredity 110: 194-204.

Ferree PM, Barbash DA. 2009. Species-Specific Heterochromatin Prevents Mitotic Chromosome Segregation to Cause Hybrid Lethality in Drosophila (MAF Noor, Ed.). PLoS Biology 7: e1000234.

Flavell AJ, Dunbar E, Anderson R, Pearce SR, Hartley R, Kumar A. 1992. Ty1-copia group retrotransposons are ubiquitous and heterogeneous in higher plants. Nucleic Acids Research 20: 36393644 .

Flutre T, Duprat E, Feuillet C, Quesneville H. 2011. Considering transposable element diversification in de novo annotation approaches (Y Xu, Ed.). PLoS ONE 6.

Fry K, Salser W. 1977. Nucleotide Sequences of HS-a Satellite DNA from Kangaroo Rat Dipodomys ordii and Characterization of Similar Sequences in Other Rodents. Cell 12: 1069-1084.

Garrido-Ramos MA. 2015. Satellite DNA in plants: more than just rubbish. Cytogenetic and Genome Research 146: 153-170.

Garrido-Ramos M. 2017. Satellite DNA: an evolving topic. Genes 8: 230.

Gladstones JS, Atkins CA, Hamblin J (Eds.). 1998. Lupins as crop plants: biology, production, and utilization. Wallingford, Oxon, UK; New York, NY, USA: CAB International.

Grandbastien M-A, Audeon C, Bonnivard E, Casacuberta JM, Chalhoub B, Costa A-PP, Le QH, Melayah D, Petit M, Poncet C, et al. 2005. Stress activation and genomic impact of Tnt1 retrotransposons in Solanaceae. Cytogenetic and Genome Research 110: 229-241.

Gregory TR. 2005. The C-value Enigma in Plants and Animals: A Review of Parallels and an Appeal for Partnership. Annals of Botany 95: 133-146.

Greilhuber J, Borsch T, Müller K, Worberg A, Porembski S, Barthlott W. 2006. Smallest Angiosperm Genomes Found in Lentibulariaceae, with Chromosomes of Bacterial Size. Plant Biology 8: 770-777.

Hane JK, Ming Y, Kamphuis LG, Nelson MN, Garg G, Atkins CA, Bayer PE, Bravo A, Bringans S, Cannon S, et al. 2017. A comprehensive draft genome sequence for lupin (Lupinus angustifolius ), an emerging health food: insights into plant-microbe interactions and legume evolution. Plant Biotechnology Journal 15: 318-330.

Hawkins JS, Kim H, Nason JD, Wing RA, Wendel JF. 2006. Differential lineage-specific amplification of transposable elements is responsible for genome size variation in Gossypium. Genome Research 16: $1252-1261$

Hawkins JS, Proulx SR, Rapp RA, Wendel JF. 2009. Rapid DNA loss as a counterbalance to genome expansion through retrotransposon proliferation in plants. Proceedings of the National Academy of Sciences 106: 17811-17816. 
Heitkam T, Petrasch S, Zakrzewski F, Kögler A, Wenke T, Wanke S, Schmidt T. 2015. Nextgeneration sequencing reveals differentially amplified tandem repeats as a major genome component of Northern Europe's oldest Camellia japonica. Chromosome Research 23: 791-806.

Hoang DT, Chernomor O, von Haeseler A, Quang Minh B, Sy Vinh L. 2017. Ufboot2: Improving The Ultrafast Bootstrap Approximation. Molecular Biology and Evolution 32: 518-522.

Hosaka A, Kakutani T. 2018. Transposable elements, genome evolution and transgenerational epigenetic variation. Current Opinion in Genetics \& Development 49: 43-48.

Hřibová E, Neumann P, Matsumoto T, Roux N, Macas J, Doležel J. 2010. Repetitive part of the banana (Musa acuminata) genome investigated by low-depth 454 sequencing. BMC Plant Biology 10.

Hu TT, Pattyn P, Bakker EG, Cao J, Cheng J-F, Clark RM, Fahlgren N, Fawcett JA, Grimwood J, Gundlach $\mathrm{H}$, et al. 2011. The Arabidopsis lyrata genome sequence and the basis of rapid genome size change. Nature Genetics 43: 476-481.

Jiang N, Bao Z, Zhang X, Hirochika H, Eddy SR, McCouch SR, Wessler SR. 2003. An active DNA transposon family in rice. Nature 421: 163-167.

Jiang N, Feschotte C, Zhang X, Wessler SR. 2004. Using rice to understand the origin and amplification of miniature inverted repeat transposable elements (MITEs). Current Opinion in Plant Biology 7: $115-119$

Kalendar R, Tanskanen J, Immonen S, Nevo E, Schulman AH. 2000. Genome evolution of wild barley (Hordeum spontaneum) by BARE-1 retrotransposon dynamics in response to sharp microclimatic divergence. Proceedings of the National Academy of Sciences 97: 6603-6607.

Kalyaanamoorthy S, Minh BQ, Wong TKF, von Haeseler A, Jermiin LS. 2017. ModelFinder: fast model selection for accurate phylogenetic estimates. Nature Methods 14: 587-589.

Kamphuis LG, Hane JK, Nelson MN, Gao L, Atkins CA, Singh KB. 2015. Transcriptome sequencing of different narrow-leafed lupin tissue types provides a comprehensive uni-gene assembly and extensive gene-based molecular markers. Plant Biotechnology Journal 13: 14-25.

Kashkush K, Feldman M, Levy AA. 2003. Transcriptional activation of retrotransposons alters the expression of adjacent genes in wheat. Nature Genetics 33: 102-106.

Katoh K, Standley DM. 2013. MAFFT multiple sequence alignment software version 7: improvements in performance and usability. Molecular Biology and Evolution 30: 772-780.

Keller J, Imperial J, Ruiz-Argüeso T, Privet K, Lima O, Michon-Coudouel S, Biget M, Salmon A, Aïnouche A, Cabello-Hurtado F. 2018. RNA sequencing and analysis of three Lupinus nodulomes provide new insights into specific host-symbiont relationships with compatible and incompatible Bradyrhizobium strains. Plant Science 266: 102-116.

Kroc M, Koczyk G, Święcicki W, Kilian A, Nelson MN. 2014. New evidence of ancestral polyploidy in the Genistoid legume Lupinus angustifolius L. (narrow-leafed lupin). Theoretical and Applied Genetics 127: 1237-1249.

Krzywinski M, Schein J, Birol I, Connors J, Gascoyne R, Horsman D, Jones SJ, Marra MA. 2009. Circos: An information aesthetic for comparative genomics. Genome Research 19: 1639-1645. 
Kumar A, Bennetzen JL. 1999. Plant retrotransposons. Annual Review of Genetics 33: 479-532.

Leitch AR, Leitch IJ. 2008. Genomic plasticity and the diversity of polyploid plants. Science 320: 481483 .

Lerat E. 2010. Identifying repeats and transposable elements in sequenced genomes: how to find your way through the dense forest of programs. Heredity 104: 520-533.

Levinson G, Gutman G. 1987. Slipped-strand mispairing: a major mechanism for DNA sequence evolution. Molecular Biology and Evolution 4: 203-221.

Li Y-C. 2004. Microsatellites Within Genes: Structure, Function, and Evolution. Molecular Biology and Evolution 21: 991-1007.

Lim KG, Kwoh CK, Hsu LY, Wirawan A. 2013. Review of tandem repeat search tools: a systematic approach to evaluating algorithmic performance. Briefings in Bioinformatics 14: 67-81.

Lippman Z, Gendrel A-V, Black M, Vaughn MW, Dedhia N, Richard McCombie W, Lavine K, Mittal V, May B, Kasschau KD, et al. 2004. Role of transposable elements in heterochromatin and epigenetic control. Nature 430: 471-476.

Lisch D. 2009. Epigenetic regulation of transposable elements in plants. Annual Review of Plant Biology 60: 43-66.

Lisch D. 2013. How important are transposons for plant evolution? Nature Reviews Genetics 14: 4961.

Liu B, Wendel JF. 2000. Retrotransposon activation followed by rapid repression in introgressed rice plants. Genome 43: 874-880.

Lönnig W-E, Saedler H. 1997. Plant transposons: contributors to evolution? Gene 205: 245-253.

Lower SS, McGurk MP, Clark AG, Barbash DA. 2018. Satellite DNA evolution: old ideas, new approaches. Current Opinion in Genetics \& Development 49: 70-78.

Lynch VJ, Nnamani MC, Kapusta A, Brayer K, Plaza SL, Mazur EC, Emera D, Sheikh SZ, Grützner F, Bauersachs S, et al. 2015. Ancient Transposable Elements Transformed the Uterine Regulatory Landscape and Transcriptome during the Evolution of Mammalian Pregnancy. Cell Reports 10: 551-561.

Ma J, Bennetzen JL. 2004. Rapid recent growth and divergence of rice nuclear genomes. Proceedings of the National Academy of Sciences 101: 12404-12410.

Macas J, Neumann P, Navrátilová A. 2007. Repetitive DNA in the pea (Pisum sativum L.) genome: comprehensive characterization using 454 sequencing and comparison to soybean and Medicago truncatula. BMC Genomics 8.

Mahé F. 2009. Phylogénie, éléments transposables et évolution de la taille des génomes chez les lupins.

Mahé F, Pascual H, Coriton O, Huteau V, Navarro Perris A, Misset M-T, Aïnouche A. 2011. New data and phylogenetic placement of the enigmatic Old World lupin: Lupinus mariae-josephi H. Pascual. Genetic Resources and Crop Evolution 58: 101-114. 
Mayer KFX, Martis M, Hedley PE, Šimková H, Liu H, Morris JA, Steuernagel B, Taudien S, Roessner $\mathrm{S}$, Gundlach H, et al. 2011. Unlocking the Barley Genome by Chromosomal and Comparative Genomics. The Plant Cell 23: 1249-1263.

Metzgar D, Bytof J, Wills C. 2000. Selection Against Frameshift Mutations Limits Microsatellite Expansion in Coding DNA. Genome Research: 9.

Morgante M, Brunner S, Pea G, Fengler K, Zuccolo A, Rafalski A. 2005. Gene duplication and exon shuffling by helitron-like transposons generate intraspecies diversity in maize. Nature Genetics 37: 997-1002.

Naganowska B. 2003. Nuclear DNA Content Variation and Species Relationships in the Genus Lupinus (Fabaceae). Annals of Botany 92: 349-355.

Naganowska B, Wolko B, Śliwińska E, Kaczmarek Z, Schifino-Wittmann MT. 2005. 2C DNA variation and relationships among New World species of the genus Lupinus (Fabaceae). Plant Systematics and Evolution 256: 147-157.

Nguyen L-T, Schmidt HA, von Haeseler A, Minh BQ. 2015. IQ-TREE: A Fast and Effective Stochastic Algorithm for Estimating Maximum-Likelihood Phylogenies. Molecular Biology and Evolution 32: 268-274.

Novák P, Ávila Robledillo L, Kobližzová A, Vrbová I, Neumann P, Macas J. 2017. TAREAN: a computational tool for identification and characterization of satellite DNA from unassembled short reads. Nucleic Acids Research 45

Novák P, Neumann P, Macas J. 2010. Graph-based clustering and characterization of repetitive sequences in next-generation sequencing data. BMC Bioinformatics 11.

Novak P, Neumann P, Pech J, Steinhaisl J, Macas J. 2013. RepeatExplorer: a Galaxy-based web server for genome-wide characterization of eukaryotic repetitive elements from next-generation sequence reads. Bioinformatics 29: 792-793.

Oliveira EJ, Pádua JG, Zucchi MI, Vencovsky R, Vieira MLC. 2006. Origin, evolution and genome distribution of microsatellites. Genetics and Molecular Biology 29: 294-307.

Oliver KR, McComb JA, Greene WK. 2013. Transposable elements: powerful contributors to Angiosperm evolution and diversity. Genome Biology and Evolution 5: 1886-1901.

Orgel LE, Crick FH, Sapienza C. 1980. Selfish DNA. Nature 288: 645-646.

O'Rourke JA, Yang SS, Miller SS, Bucciarelli B, Liu J, Rydeen A, Bozsoki Z, Uhde-Stone C, Tu ZJ, Allan D, et al. 2013. An RNA-Seq Transcriptome Analysis of Orthophosphate-Deficient White Lupin Reveals Novel Insights into Phosphorus Acclimation in Plants. Plant Physiology 161: 705-724.

Parra-González LB, Aravena-Abarzúa GA, Navarro-Navarro CS, Udall J, Maughan J, Peterson LM, Salvo-Garrido HE, Maureira-Butler IJ. 2012. Yellow lupin (Lupinus luteus L.) transcriptome sequencing: molecular marker development and comparative studies. BMC Genomics 13: 425.

Pellicer J, Oriane Hidalgo, Steven Dodsworth, Ilia Leitch. 2018. Genome Size Diversity and Its Impact on the Evolution of Land Plants. Genes 9: 88. 
Petes TD. 1980. Unequal meiotic recombination within tandem arrays of yeast ribosomal DNA genes. Cell 19: 765-774.

Piednoël M, Carrete-Vega G, Renner SS. 2013. Characterization of the LTR retrotransposon repertoire of a plant clade of six diploid and one tetraploid species. The Plant Journal 75: 699-709.

Piegu B, Guyot R, Picault N, Roulin A, Saniyal A, Kim H, Collura K, Brar DS, Jackson S, Wing RA, et al. 2006. Doubling genome size without polyploidization: Dynamics of retrotransposition-driven genomic expansions in Oryza australiensis, a wild relative of rice. Genome Research 16: 1262-1269.

Plohl M, Mestrovic N, Mravinac B. 2012. Satellite DNA Evolution. In: Garrido-Ramos MA, ed. Genome Dynamics. Basel: S. KARGER AG, 126-152.

Priyam A, Woodcroft BJ, Rai V, Munagala A, Moghul I, Ter F, Gibbins MA, Moon H, Leonard G, Rumpf W \& Wurm Y. 2015. Sequenceserver: a modern graphical user interface for custom BLAST databases. biorxiv doi: 10.1101/033142.

Quesneville H, Bergman CM, Andrieu O, Autard D, Nouaud D, Ashburner M, Anxolabehere D. 2005. Combined evidence annotation of transposable elements in genome sequences. PLoS Computational Biology 1: 166-175.

Raman R, Cowley RB, Raman HD, Luckett DJ. 2014. Analyses using SSR and DArT molecular markers reveal that Ethiopian accessions of white lupin (Lupinus albus L.) represent a unique gene pool. Open J Genet. 4:87-98.

Renny-Byfield S, Chester M, Kovarik A, Le Comber SC, Grandbastien M-A, Deloger M, Nichols RA, Macas J, Novak P, Chase MW, et al. 2011. Next generation sequencing reveals genome downsizing in allotetraploid Nicotiana tabacum, predominantly through the elimination of paternally derived repetitive DNAs. Molecular Biology and Evolution 28: 2843-2854.

Renny-Byfield S, Gallagher JP, Grover CE, Szadkowski E, Page JT, Udall JA, Wang X, Paterson AH, Wendel JF. 2014. Ancient gene duplicates in Gossypium (Cotton) exhibit near-complete expression divergence. Genome Biology and Evolution 6: 559-571.

Renny-Byfield S, Wendel JF. 2014. Doubling down on genomes: polyploidy and crop plants. American Journal of Botany 101: 1711-1725.

Ruiz-Ruano FJ, López-León MD, Cabrero J, Camacho JPM. 2016. High-throughput analysis of the satellitome illuminates satellite DNA evolution. Scientific Reports 6.

Satović E, Vojvoda Zeljko T, Plohl M. 2018. Characteristics and evolution of satellite DNA sequences in bivalve mollusks. The European Zoological Journal 85: 94-103.

Schmuths H. 2004. Genome Size Variation among Accessions of Arabidopsis thaliana. Annals of Botany 93: 317-321.

Sequencing Project IRG. 2005. The map-based sequence of the rice genome. Nature 436: 793-800.

Shi J, Huang S, Fu D, Yu J, Wang X, Hua W, Liu S, Liu G, Wang H. 2013. Evolutionary Dynamics of Microsatellite Distribution in Plants: Insight from the Comparison of Sequenced Brassica, Arabidopsis and Other Angiosperm Species (BA Vinatzer, Ed.). PLoS ONE 8: e59988. 
Sievers F, Wilm A, Dineen D, Gibson TJ, Karplus K, Li W, Lopez R, McWilliam H, Remmert M, Soding J, et al. 2014. Fast, scalable generation of high-quality protein multiple sequence alignments using Clustal Omega. Molecular Systems Biology 7: 539-539.

Slotkin RK, Martienssen R. 2007. Transposable elements and the epigenetic regulation of the genome Nature Reviews Genetics 8: 272-285.

Soltis DE, Albert VA, Leebens-Mack J, Bell CD, Paterson AH, Zheng C, Sankoff D, dePamphilis CW, Wall PK, Soltis PS. 2009. Polyploidy and angiosperm diversification. American Journal of Botany 96 : 336-348

Streelman JT, Kocher TD. 2002. Microsatellite variation associated with prolactin expression and growth of salt-challenged tilapia. Physiological Genomics 9: 1-4.

Thomas CA. 1971. The Genetic Organization of Chromosomes. Annual Review of Genetics 5: 237256.

Toth G. 2000. Microsatellites in Different Eukaryotic Genomes: Survey and Analysis. Genome Research 10: 967-981.

Treangen TJ, Salzberg SL. 2011. Repetitive DNA and next-generation sequencing: computational challenges and solutions. Nature Reviews Genetics 13: 36-46.

Usai G, Mascagni F, Natali L, Giordani T, Cavallini A. 2017. Comparative genome-wide analysis of repetitive DNA in the genus Populus L. Tree Genetics \& Genomes 13: 96

Vicient CM, Suoniemi A, Anamthawat-Jónsson K, Tanskanen J, Beharav A, Nevo E, Schulman AH 1999. Retrotransposon BARE-1 and Its Role in Genome Evolution in the Genus Hordeum. The Plant Cell 11: 17.

Vu GTH, Schmutzer T, Bull F, Cao HX, Fuchs J, Tran TD, Jovtchev G, Pistrick K, Stein N, Pecinka A, et al. 2015. Comparative Genome Analysis Reveals Divergent Genome Size Evolution in a Carnivorous Plant Genus. The Plant Genome 8(3): 1-14.

Wajid B, Serpedin E. 2012. Review of General Algorithmic Features for Genome Assemblers for Next Generation Sequencers. Genomics, Proteomics \& Bioinformatics 10: 58-73.

Wendel JF, Jackson SA, Meyers BC, Wing RA. 2016. Evolution of plant genome architecture. Genome Biology 17: 37 .

Wessler SR. 2006. Transposable elements and the evolution of eukaryotic genomes. Proceedings of the National Academy of Sciences 103: 17600-17601.

Wicker T, Gundlach H, Spannagl M, Uauy C, Borrill P, Ramírez-González RH, De Oliveira R, Mayer KFX, Paux E, Choulet F. 2018. Impact of transposable elements on genome structure and evolution in bread wheat. Genome Biology 19(1):103.

Wicker T, Sabot F, Hua-Van A, Bennetzen JL, Capy P, Chalhoub B, Flavell A, Leroy P, Morgante M, Panaud $\mathrm{O}$, et al. 2007. A unified classification system for eukaryotic transposable elements. Nature Reviews Genetics 8: 973-982.

Wolko B, Weeden NF. 1989. Estimation of Lupinus genome polyploidy on the basis of isozymic loci number. Genetica Polonica 30: 165-171. 
Wu DD, Ruban A, Fuchs J, Macas J, Novak P, Vaio M, Zhou YH, Houben A. 2019. Nondisjunction and unequal spindle organization accompany the drive of Aegilops speltoides B chromosomes. New Phytologist 223:1340-1352

Yaakov B, Kashkush K. 2012. Mobilization of Stowaway-like MITEs in newly formed allohexaploid wheat species. Plant Molecular Biology 80: 419-427. 